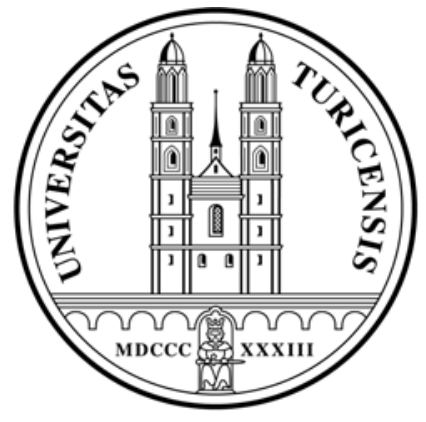

Institute for Empirical Research in Economics

University of Zurich

Working Paper Series

ISSN 1424-0459

Working Paper No. 408

Technology shocks and aggregate fluctuations in an estimated hybrid RBC model

Jim Malley and Ulrich Woitek

April 2009 


\title{
Technology shocks and aggregate fluctuations in an estimated hybrid RBC model*
}

\author{
Jim Malley \\ University of Glasgow and CESifo \\ Ulrich Woitek \\ University of Zurich and CESifo
}

April 5, 2009

\begin{abstract}
This paper contributes to the on-going empirical debate regarding the role of the RBC model and in particular of technology shocks in explaining aggregate fluctuations. To this end we estimate the model's posterior density using Markov-Chain Monte-Carlo (MCMC) methods. Within this framework we extend Ireland's $(2001,2004)$ hybrid estimation approach to allow for a vector autoregressive moving average (VARMA) process to describe the movements and co-movements of the model's errors not explained by the basic RBC model. The results of marginal likelihood ratio tests reveal that the more general model of the errors significantly improves the model's fit relative to the VAR and AR alternatives. Moreover, despite setting the RBC model a more difficult task under the VARMA specification, our analysis, based on forecast error and spectral decompositions, suggests that the RBC model is still capable of explaining a significant fraction of the observed variation in macroeconomic aggregates in the post-war U.S. economy.
\end{abstract}

Keywords: Real Business Cycle, Bayesian estimation, VARMA errors JEL codes: C11, C52, E32

${ }^{*}$ We would like to thank seminar participants at the Department of Economics, University of Glasgow for helpful comments and suggestions. The usual disclaimer applies. 


\section{Introduction}

The role of technology shocks as a leading determinant of business cycles continues to be a heated debate over their ability to explain the observed variation of macroeconomic aggregates in the postwar US economy. While a number of authors as early as Eichenbaum (1991) and more recently Ireland (2004) and Chari et al. (2007a), acknowledge a large degree of uncertainty associated with these estimates, they do not rule out the possibility that technology may still have an important role to play.

For example, Eichenbaum (1991 p. 608) states, "What the data are actually telling us is that, while technology shocks almost certainly play some role in generating the business cycle, there is an enormous amount of uncertainty about just what percent of aggregate fluctuations they actually do account for. The answer could be $70 \%$ as Kydland and Prescott (1989) [1991] claim, but the data contain almost no evidence against either the view that the answer is really $5 \%$ or that the answer is really $200 \%$ ".

In a similar vein, when reviewing the results from a vast range of studies based on calibration and econometric estimation, ${ }^{1}$ Chari et al. (2007a p. 39) argue, "The message we get from these and related studies in the business cycle literature is that a plausible case can be made that in the US data, technology shocks account for essentially any value between zero and $100 \%$ of output variance. Put differently, when the US data are viewed through the lens of the growth model, dismissing any estimate in this range is unreasonable".

Ireland's (2004) findings however, are less pessimistic than both Eichenbaum (1991) and Chari et al. (2007). He remarks, "Even if the true fraction of output variation explained by the real business cycle model is two standard errors less than the point estimate of $90 \%$, for instance, that fraction remains greater than 60\%" (Ireland 2004, p. 1213).

In sharp contrast, a series of influential studies by Galí (1999), Galí and Rabanal (2005) and Francis and Ramey (2005), are far less circumspect in their view regarding the usefulness of the basic RBC model as a framework in which to study business cycles. For example, Francis and Ramey (2005, p. 1380) proclaim that "the original technology-driven real business cycle hypothesis does appear to be dead". These studies arrive at their conclusions via a differenced structural vector autoregressive (DSVAR) model using US data and find, contrary to the predictions of the standard RBC model, that

\footnotetext{
${ }^{1}$ The econometric studies referred to by Chari et al. (2007a) include those using both generalized method of moments (GMM) and maximum likelihood (ML) methods to estimate an RBC model as well as studies based on structural vector autoregressions (SVAR) employing long-run restrictions.
} 
hours worked falls in response to a positive technology shock. They also find that technology shocks do not generally play a prominent role in accounting for the variance of output.

Despite the clear messages arising from the DSVAR studies, the findings by Christiano et al. (2003) and more recently by Chari et al. (2007a) suggest that perhaps these results are not robust. For example, Christiano et al. (2003), using an SVAR specified in levels (LSVAR), are able to reverse the impulse response results of the DSVAR studies. Chari et al. (2007a) take an even stronger position and suggest that the findings of both specifications of the SVAR should be viewed with some suspicion since they suffer from lag-truncation bias. Instead they argue that an alternative SVAR approach based on the work of Sims (1989) and Cogley and Nason (1995) as well as the business cycle accounting approach of Chari et al. (2007b) are potentially more fruitful methods for appealing to the data to help develop business cycle theory.

In contrast to the SVAR method, which relies only loosely on economic theory, another strand of the literature views the RBC model's equilibrium conditions and their associated "cross-equation restrictions" as a likelihood function which can be maximized (see, e.g. Sargent (1989)). ${ }^{2}$ A recent set of studies in the likelihood estimation literature which are particularly relevant for our work are by Ireland $(2001,2004)$ who proposes a hybrid approach to model estimation. This method is motivated by the desire to avoid the problem of stochastic singularity due to the presence of only one source of uncertainty in the basic RBC model. To this end Ireland builds directly on the work of Sargent (1989), Altug (1989), McGrattan (1994), Hall (1996) and McGrattan et al. (1997) by also adding scalar AR(1) errors to the observation equations of the state-space representation of the RBC model. However in contrast to these authors, he further allows for cross-equation correlation between these errors using a VAR(1) structure. $^{3}$

Ireland convincingly argues, "The method takes as its starting point a fully-specifed DSGE model, but also admits that while this model may be powerful enough to account for and explain many key features of the US data, it remains too stylized to possibly capture all of the dynamics that can be

\footnotetext{
${ }^{2}$ Ruge-Murcia (2007) provides an excellent overview of this literature and extensive references relating to classical and Bayesian estimation of both linear and nonlinear dynamic equilibrium models.

${ }^{3}$ Solving the stochastic singularity problem associated with maximum likelihood estimation of the linearized model can also be tackled by introducing structural shocks until the number of shocks is equal to the number of observables in the model (see, e.g. Bencivenga (1992), Ireland (1997, 2001a,b, 2002), DeJong et al. (2000a,b), Kim (2000), Schorfheide (2000), Smets and Wouters (2003) and Bouakez et al. (2005)).
} 
found in the data. Hence, it augments the DSGE model so that its residuals - meaning the movements in the data that the theory cannot explain - are described by a VAR, making estimation, hypothesis testing, and forecasting feasible" (Ireland 2004, p. 1206). He goes on to state that while the residuals may account for measurement errors, "... they can also be interpreted more liberally as capturing all of the movements and co-movements in the data that the real business cycle model, because of its elegance and simplicity, cannot explain" (Ireland 2004, p. 1206).

With a view to contributing to the still clearly open question regarding the role of the technology-driven RBC model in explaining aggregate fluctuations, we apply and extend the Ireland $(2001,2004)$ hybrid approach to model estimation. Consistent with Ireland's objective to reconcile the limited dynamics in the RBC model with the data, we extend his method to allow for a $\operatorname{VARMA}(1,1)$ representation of the residuals. Since a stationary $\operatorname{VARMA}(1,1)$ has both infinite VAR and VMA representations, it allows for a much richer representation of the dynamic interactions between the residuals. Accounting for these can lead to improvements in model fit to the historical data and hence more accurate predictions for the various diagnostics used to asses the explanatory power of the RBC model, e.g. forecast error and spectral decompositions. Realizing these potential gains is clearly critical in light of the objectives of this paper.

In contrast to Ireland $(2001,2004)$, we do not employ classical maximum likelihood methods to obtain parameter estimates for the competing models we consider but instead use simulation methods pioneered in dynamic macroeconomics by DeJong et al. (2000a,b). Given that Ireland's approach makes use of prior information when estimating the likelihood function, simulation methods are a natural extension since they provide a framework for formally incorporating both parameter and model uncertainty.

Our main findings are: (i) the $\operatorname{VARMA}(1,1)$ specification of the errors significantly improves the basic RBC model's fit to the historical data relative to the $\operatorname{VAR}(1)$ and $\operatorname{AR}(1)$ alternatives; (ii) despite setting the RBC model a more difficult task under the VARMA $(1,1)$ specification, technological shocks are still capable of explaining a significant share of the observed variation in output and its components over shorter- and longer-forecast horizons as well as hours at shorter horizons; (iii) the RBC model generally does a relatively better job at matching low and high frequency cyclical movements in the data than at the traditional business cycles ranges; and (iv) the degree of uncertainty associated with the explanatory power of the RBC model much discussed in the literature is perhaps overstated since we find that estimated posterior distributions for the forecast error and spectral decompositions to be quite concentrated. 


\section{Basic RBC Model}

Following is a brief sketch of the structure and approximate solution of a prototypical RBC model (see Hansen (1985)). This model or simple variations thereof are frequently used when developing and illustrating alternative solution and estimation procedures (for examples of the later see, e.g. RugeMurcia (2007), Ireland (2001, 2004) and Dejong et al. (2000b)).

Given that the model and its solution are well known, the main purpose of this section is simply to fix ideas, notation and variable definitions which will be used in the estimation and analysis which follows. Moreover, since one of our objectives is to extend Ireland's method, we will use the exact variant of the Hansen (1985) model employed in Ireland (2004) to facilitate transparent comparability. ${ }^{4}$ Accordingly, we leave out many of the details which can be found in Ireland (2004) and cross-reference these as required below.

\section{$2.1 \quad$ Households}

The representative household maximizes expected discounted lifetime utility

$$
\max _{\left\{C_{t}, H_{t}\right\}_{t=0}^{\infty}} E_{0} \sum_{t=0}^{\infty} \beta^{t}\left[\ln \left(C_{t}\right)-\gamma H_{t}\right], \beta \in(0,1), \gamma>0
$$

where $E_{0}$ is the conditional expectations operator; $C_{t}$ is consumption at time $t, H_{t}$ is hours worked, $\beta$ is the discount factor and $\gamma$ is a parameter governing the linearity of hours.

The household faces the following budget constraint in every period

$$
r_{t} K_{t}+w_{t} H_{t}+\Pi_{t}=C_{t}+I_{t}
$$

where $K_{t}$ is the quantity of physical capital at the beginning of period $t ; r_{t}$ is the rental rate of capital; $w_{t}$ is the wage rate of labour; $\Pi_{t}$ is the household's share of profits of the representative firm; and $I_{t}$ is investment.

Capital accumulates according to the standard evolution equation

$$
K_{t+1}=I_{t}+(1-\delta) K_{t}, \delta \in(0,1)
$$

where $\delta$ is the constant rate of depreciation.

\footnotetext{
${ }^{4}$ Consistent with this choice we also use the US data employed in Ireland (2004), see www2.bc.edu/ irelandp/. Note that the quarterly observation period is 1948:1-2002:2.
} 


\section{$2.2 \quad$ Firms}

The representative firm produces a consumption good, $Y_{t}$ and maximizes (from $t=0 \ldots \infty$ ) as series of static profit functions

$$
\Pi_{t}=Y_{t}-r_{t} K_{t}-w_{t} H_{t}
$$

subject to a series of technology constraints

$$
Y_{t}=A_{t} K_{t}^{\theta}\left(\eta^{t} H_{t}\right)^{1-\theta}, \theta \in(0,1), \eta>1
$$

where $A_{t}$ is Hick's neutral technological progress, $\theta$ is the productivity of private capital and $\eta$ is the gross rate of labour-augmenting technological progress.

\subsection{Aggregate resource constraint and technology}

In each period $t=0,1,2, \ldots$ the goods market clearing condition holds, i.e.

$$
Y_{t}=C_{t}+I_{t}
$$

Finally, the exogenous first-order stochastic Markov process for technology, $A_{t}$ is given by

$$
\begin{gathered}
A_{t+1}=A^{(1-\rho)} A_{t}^{\rho} e^{\varepsilon_{t+1}}, \rho \in(0,1) \\
\varepsilon_{t} \sim N\left(0, \sigma_{\varepsilon}^{2}\right)
\end{gathered}
$$

where $\rho$ is an $\operatorname{AR}(1)$ parameter and $\sigma_{\varepsilon}^{2}$ is the constant variance of the stochastic errors, $\varepsilon_{t}$.

\subsection{Equilibrium conditions and model solution}

Given the above setup the representative household chooses $\left\{Y_{t}, C_{t}, I_{t}, H_{t}\right.$, $\left.K_{t+1}\right\}_{t=0}^{\infty}$ to maximize utility (for given $K_{0}, A_{0}$ ) subject to $(3,5,6,7)$ and the firm chooses $\left\{H_{t}, K_{t+1}\right\}_{t=0}^{\infty}$ to maximize profits subject to (5); yielding a set of non-stationary equilibrium allocations. ${ }^{5}$ The linearized stationary

\footnotetext{
${ }^{5}$ See Ireland (2004, p. 1208) for the explicit form of these conditions.
} 
representation of these for all $t=0,1,2, \ldots$ is given by:

$$
\begin{aligned}
\widehat{y}_{t} & =\widehat{a}_{t}+\theta \widehat{k}_{t}+(1-\theta) \widehat{h}_{t} \\
\widehat{a}_{t} & =\rho \widehat{a}_{t-1}+\varepsilon_{t} \\
(\eta / \beta-1+\delta) \widehat{y}_{t} & =[(\eta / \beta-1+\delta)-\theta(\eta-1+\delta)] \widehat{c}_{t}+\theta(\eta-1+\delta) \widehat{i}_{t} \\
\eta \widehat{k}_{t+1} & =(1-\delta) \widehat{k}_{t}+(\eta-1+\delta) \widehat{i} \\
\widehat{c}_{t}+\widehat{h}_{t} & =\widehat{y}_{t} \\
-\frac{\eta}{\beta} \hat{c}_{t} & =-\frac{\eta}{\beta} E_{t} \hat{c}_{t+1}+\left(\frac{\eta}{\beta}-1+\delta\right) E_{t} \hat{y}_{t+1}-\left(\frac{\eta}{\beta}-1+\delta\right) \hat{k}_{t+1}
\end{aligned}
$$

where $y_{t}=Y_{t} / \eta^{t}, c_{t}=C_{t} / \eta^{t}, i_{t}=I_{t} / \eta^{t}, k_{t}=K_{t} / \eta^{t}, h_{t} \equiv H_{t}, a_{t} \equiv A_{t}$ and for any stationary variable $x_{t}, \widehat{x}_{t}=\ln \left(\frac{x_{t}}{x}\right)$. Finally, non-time subscripted variables, $x$, refer to deterministic steady-state values. ${ }^{6}$

The policy functions comprising the solution of the above linear system of stochastic difference equations can be written in state-space form as

$$
\begin{aligned}
\mathbf{y}_{t} & =\left(\begin{array}{ll}
\mathbf{l}_{z k} & \mathbf{l}_{z x}
\end{array}\right)\left(\begin{array}{l}
\hat{k}_{t} \\
\hat{a}_{t}
\end{array}\right) \\
\left(\begin{array}{c}
\hat{k}_{t} \\
\hat{a}_{t}
\end{array}\right) & =\left(\begin{array}{cc}
l_{k k} & l_{k x} \\
0 & \rho
\end{array}\right)\left(\begin{array}{l}
\hat{k}_{t-1} \\
\hat{a}_{t-1}
\end{array}\right)+\left(\begin{array}{l}
0 \\
1
\end{array}\right) \epsilon_{t}
\end{aligned}
$$

or

$$
\begin{aligned}
\mathbf{y}_{t} & =\mathbf{Z} \boldsymbol{\alpha}_{t} \\
\boldsymbol{\alpha}_{t} & =\mathbf{T} \boldsymbol{\alpha}_{t-1}+\mathbf{G} \epsilon_{t} .
\end{aligned}
$$

where $\mathbf{y}_{t}=\left(\begin{array}{lll}\widehat{y}_{t} & \widehat{c}_{t} & \widehat{h}_{t}\end{array}\right)^{\prime}$ and the elements of $\mathbf{Z}$ and $\mathbf{T}$ contain convolutions the model's structural parameters.

\section{$3 \quad$ Econometric Setup}

In this section we first provide some motivation for the more flexible error structure we propose. We then add $\operatorname{AR}(1), \operatorname{VAR}(1)$ and $\operatorname{VARMA}(1,1)$ errors to (9) and derive the models' corresponding likelihood functions. To obtain the latter we employ the Kalman filter given that the capital stock, technology, and the various measurement/specification errors are treated as unobservables.

\footnotetext{
${ }^{6}$ Again, see Ireland (2004, p. 1221) for the details of the unique steady-state equilibrium.
} 


\subsection{Motivation for VARMA structure}

Consider the following decomposition of a vector of measured data, $\mathbf{y}_{t}^{m}$ into the part captured by a structural economic model, $\mathbf{y}_{t}^{s}$, and another vector not captured by the model, $\boldsymbol{\epsilon}_{t}$ :

$$
\mathbf{y}_{t}^{m}=\mathbf{y}_{t}^{s}+\boldsymbol{\epsilon}_{t} .
$$

In other words, the non-structural component, $\boldsymbol{\epsilon}_{t}$, consisting of measurement and specification errors represents an unobservable wedge between the measured data and the structural model. In contrast to Chari et al. (2007b), we do not give the wedge a structural interpretation, but instead follow, e.g. Sargent (1989) and Ireland (2004) and as a first step use a AR(1)/VAR(1) structure for $\boldsymbol{\epsilon}_{t}{ }^{7}$ :

$$
\begin{aligned}
\mathbf{y}_{t}^{m} & =\mathbf{y}_{t}^{s}+\boldsymbol{\epsilon}_{t} \\
\boldsymbol{\epsilon}_{t} & =\boldsymbol{\iota}_{1} \boldsymbol{\epsilon}_{t-1}+\boldsymbol{\zeta}_{t} \\
\left(1-\boldsymbol{\iota}_{1} L\right) \boldsymbol{\epsilon}_{t} & =\boldsymbol{\zeta}_{t} .
\end{aligned}
$$

Let's next assume that the dynamic structure of the wedge can be approximated by a more general $\operatorname{VARMA}(1,1)$ process

$$
\begin{aligned}
\mathbf{y}_{t}^{m} & =\mathbf{y}_{t}^{s}+\boldsymbol{\epsilon}_{t} \\
\boldsymbol{\epsilon}_{t} & =\boldsymbol{\phi} \boldsymbol{\epsilon}_{t-1}+\boldsymbol{\zeta}_{t}+\boldsymbol{\vartheta} \boldsymbol{\zeta}_{t-1} \\
\boldsymbol{\phi}(L) \boldsymbol{\epsilon}_{t} & =\boldsymbol{\vartheta}(L) \boldsymbol{\zeta}_{t} .
\end{aligned}
$$

If the filter $\boldsymbol{\theta}(L)$ is stable and invertible, the $\operatorname{VARMA}(1,1)$ process represents a more flexible and parsimonious representation of a $\operatorname{VAR}(\infty)$ or $\operatorname{VMA}(\infty)$ process (see, e.g. Lütkepohl (1991, p. 220-223)), i.e.

$$
\begin{aligned}
\boldsymbol{\vartheta}(L)^{-1} \boldsymbol{\phi}(L) \boldsymbol{\epsilon}_{t} & =\boldsymbol{\zeta}_{t} \\
\boldsymbol{\iota}(L) \boldsymbol{\epsilon}_{t} & =\boldsymbol{\zeta}_{t} \\
\left(1-\boldsymbol{\iota}_{1} L-\iota_{2} L^{2}-\ldots\right) \boldsymbol{\epsilon}_{t} & =\boldsymbol{\zeta}_{t}
\end{aligned}
$$

This structure precludes the so called lag-truncation bias problem associated with approximating infinite order VARs with finite order representations. As pointed out in the introduction, allowing for a more general representation of the dynamic interactions between the errors can lead to improvements in model fit and hence more accurate predictions for the various diagnostic used to asses the explanatory power of the RBC model.

\footnotetext{
${ }^{7}$ Note that when the variance covariance matrix of $\boldsymbol{\zeta}_{t}$ and $\boldsymbol{\rho}_{1}$ are diagonal, the $\operatorname{AR}(1)$ structure maintains.
} 


\section{$3.2 \quad \operatorname{AR}(1) / \operatorname{VAR}(1)$ setup}

Adding an $n$-dimensional $\operatorname{VAR}(1)$ measurement/specification error, i.e. $\boldsymbol{\eta}_{t}=$ $\boldsymbol{V} \boldsymbol{\eta}_{t-1}+\boldsymbol{\nu}_{t}$, to (9) as in Ireland $(2001,2004)$ yields the following state-space representation

$$
\begin{aligned}
& \mathbf{y}_{t}=\mathbf{Z} \boldsymbol{\alpha}_{t}+\boldsymbol{\eta}_{t}=\underbrace{\left(\begin{array}{ll}
\mathbf{Z} & \mathbf{I}_{n}
\end{array}\right)}_{\tilde{\mathbf{Z}}} \underbrace{\left(\begin{array}{c}
\boldsymbol{\alpha}_{t} \\
\boldsymbol{\eta}_{t}
\end{array}\right)}_{\widetilde{\boldsymbol{\alpha}}_{t}} \\
& \underbrace{\left(\begin{array}{c}
\boldsymbol{\alpha}_{t} \\
\boldsymbol{\eta}_{t}
\end{array}\right)}_{\widetilde{\boldsymbol{\alpha}}_{t}}=\underbrace{\left(\begin{array}{cc}
\mathbf{T} & \mathbf{0} \\
\mathbf{0} & \mathbf{V}
\end{array}\right)}_{\widetilde{\mathbf{T}}} \underbrace{\left(\begin{array}{c}
\boldsymbol{\alpha}_{t-1} \\
\boldsymbol{\eta}_{t-1}
\end{array}\right)}_{\widetilde{\boldsymbol{\alpha}}_{t-1}}+\underbrace{\left(\begin{array}{cc}
\mathbf{G} & \mathbf{0} \\
\mathbf{0} & \mathbf{I}_{n}
\end{array}\right)\left(\begin{array}{c}
\epsilon_{t} \\
\boldsymbol{\nu}_{t}
\end{array}\right)}_{\boldsymbol{\zeta}_{t} \sim N(\mathbf{0}, \boldsymbol{\Sigma})} .
\end{aligned}
$$

Using the $\operatorname{VAR}(1)$ representation, an extension to a finite $\operatorname{VAR}(p)$ error structure is also straightforward (see, Lütkepohl 1991, p. 11). Also note that when the matrices $\mathbf{V}$ and $\boldsymbol{\Sigma}$ are diagonal, the AR(1) specification maintains (see, e.g. Sargent (1989)).

\subsection{VARMA(1,1) setup}

As pointed out above, if stable and invertible, the VARMA $(1,1)$ specification allows us to generalize the finite $\operatorname{VAR}(p)$ errors to a $\operatorname{VAR}(\infty)$ or $\operatorname{VMA}(\infty)$ structure thus yielding a much richer representation of the dynamic interactions between the errors. For the $\operatorname{VARMA}(1,1)$ case, i.e. $\boldsymbol{\eta}_{t}=\mathbf{V} \boldsymbol{\eta}_{t-1}+\mathbf{M} \boldsymbol{\nu}_{t-1}+\boldsymbol{\nu}_{t}$, the state-space representation in (9) becomes

$$
\begin{aligned}
& \mathbf{y}_{t}=\left(\begin{array}{ll}
\mathbf{Z} & \mathbf{H}
\end{array}\right)\left(\begin{array}{c}
\boldsymbol{\alpha}_{t} \\
\boldsymbol{\eta}_{t} \\
\boldsymbol{\nu}_{t}
\end{array}\right) \\
& \left(\begin{array}{c}
\boldsymbol{\alpha}_{t} \\
\boldsymbol{\eta}_{t} \\
\boldsymbol{\nu}_{t}
\end{array}\right)=\underbrace{\left(\begin{array}{ccc}
\mathbf{T} & \mathbf{0} & 0 \\
\mathbf{0} & \mathbf{J} & \mathbf{0} \\
\mathbf{0} & \mathbf{0} & \mathbf{0}
\end{array}\right)}_{\widetilde{\boldsymbol{\alpha}}} \underbrace{\left(\begin{array}{c}
\boldsymbol{\alpha}_{t-1} \\
\boldsymbol{\eta}_{t-1} \\
\boldsymbol{\nu}_{t-1}
\end{array}\right)}_{\widetilde{\boldsymbol{\alpha}}_{t-1}}+\underbrace{\left(\begin{array}{cc}
\mathbf{G} & \mathbf{0} \\
\mathbf{0} & \mathbf{R}
\end{array}\right)\left(\begin{array}{c}
\epsilon_{t} \\
\boldsymbol{\nu}_{t}
\end{array}\right)}_{\boldsymbol{\zeta}_{t} \sim N(\mathbf{0}, \boldsymbol{\Sigma})}
\end{aligned}
$$

where

$$
\mathbf{J}=\left(\begin{array}{cc}
\mathbf{V} & \mathbf{M} \\
\mathbf{0} & \mathbf{0}
\end{array}\right) \mathbf{R}=\left(\begin{array}{l}
\mathbf{I}_{K} \\
\mathbf{I}_{K}
\end{array}\right) \mathbf{H}=\left(\begin{array}{ll}
\mathbf{I}_{K} & \mathbf{0}
\end{array}\right)
$$

\subsection{Kalman filter}

For given initial estimates of the state vector, $\mathbf{a}_{0}$, i.e. $\mathbf{a}_{0}=E\left(\widetilde{\boldsymbol{\alpha}}_{0}\right)$ and the covariance matrix, $\mathbf{P}_{0}$, the filter consists of the following steps: 
1. prediction step

$$
\begin{aligned}
\mathbf{a}_{t \mid t-1} & =\widetilde{\mathbf{T}} \mathbf{a}_{t-1}, \\
\mathbf{P}_{t \mid t-1} & =\widetilde{\mathbf{T}} \mathbf{P}_{t-1} \widetilde{\mathbf{T}}^{\prime}+\Sigma .
\end{aligned}
$$

2. updating step

$$
\begin{aligned}
\boldsymbol{v}_{t} & =\mathbf{y}_{t}-\widetilde{\mathbf{Z}} \mathbf{a}_{t \mid t-1} \\
\mathbf{F}_{t} & =\widetilde{\mathbf{Z}} \mathbf{P}_{t \mid t-1} \widetilde{\mathbf{Z}}^{\prime} \\
\mathbf{K}_{t} & =\widetilde{\mathbf{T}} \mathbf{P}_{t \mid t-1} \widetilde{\mathbf{Z}}^{\prime} \mathbf{F}_{t}^{-1} \\
\mathbf{a}_{t} & =\widetilde{\mathbf{T}} \mathbf{a}_{t \mid t-1}+\mathbf{K}_{t} \boldsymbol{v}_{t} ; \\
\mathbf{P}_{t} & =\left(\widetilde{\mathbf{T}}-\mathbf{K}_{t} \widetilde{\mathbf{Z}}\right) \mathbf{P}_{t \mid t-1}\left(\widetilde{\mathbf{T}}-\mathbf{K}_{t} \widetilde{\mathbf{Z}}\right)^{\prime}+\boldsymbol{\Sigma}
\end{aligned}
$$

where $\boldsymbol{v}_{t}$ are the model's forecast errors. The remaining vector and matrices have either been defined above or, in the case of $\mathbf{F}_{t}$ and $\mathbf{K}_{t}$, are simply transformations of previously defined matrices. ${ }^{8}$

\subsection{Likelihood function and estimation algorithm}

We are now in a position to write the model's likelihood function as

$$
p\left(\mathbf{y}_{t, t=1}, \ldots, T \mid \psi\right)=\prod_{t=1}^{T}(2 \pi)^{-0.5 n}\left|\mathbf{F}_{t}\right|^{-0.5} \exp \left(-0.5 \boldsymbol{v}_{t}^{\prime} \mathbf{F}_{t}^{-1} \boldsymbol{v}_{t}\right)
$$

where $\boldsymbol{\psi}$ is the vector of model parameters to be estimated and $n$ is the number of measurement equations. We estimate $\boldsymbol{\psi}$ using the random walk Metropolis-Hastings algorithm (see e.g., Chib and Greenberg (1995)), setting the number of simulations to $S=60,000$ with a burn-in of 10,000 . We draw a new realization of $\boldsymbol{\psi}$ according to

$$
\boldsymbol{\psi}_{1}=\boldsymbol{\psi}_{0}+\boldsymbol{\xi}, \boldsymbol{\xi} \sim N(\mathbf{0}, \boldsymbol{\Xi})
$$

where $\boldsymbol{\Xi}$ is the proposal variance-covariance matrix. A draw $\boldsymbol{\psi}_{1}$ is accepted if

$$
\begin{aligned}
a & \geq u, u \sim U(0,1) \\
a\left(\boldsymbol{\psi}_{1}, \boldsymbol{\psi}_{0}\right) & =\min \left(\frac{p\left(\mathbf{y}_{t, t=1}, \ldots, T \mid \boldsymbol{\psi}_{1}\right) p\left(\boldsymbol{\psi}_{1}\right)}{p\left(\mathbf{y}_{t, t=1}, \ldots, T \mid \boldsymbol{\psi}_{0}\right) p\left(\boldsymbol{\psi}_{0}\right)}, 1\right),
\end{aligned}
$$

where $p(\boldsymbol{\psi})$ is the prior distribution given in Table 1 .

\footnotetext{
${ }^{8}$ See Hamilton (1994) or Harvey (1992) for further details regarding the Kalman filter.
} 
Table 1: Priors for the parameters, $\boldsymbol{\psi}$

\begin{tabular}{lll}
\hline \hline & Parameters & Restrictions \\
\hline & $\beta$ & $(0.75,1)$ \\
& $\gamma$ & $(>0)$ \\
& $\rho$ & $(0,1)$ \\
Structural & $A$ & $(0,10)$ \\
& $\delta$ & $(0,1)$ \\
& $\theta$ & $(0,1)$ \\
& $\eta$ & $(>1)$ \\
Eigenvalues (AR,VAR) & $\lambda_{\{i=1,2,3\}}$ & $(0,0.1)$ \\
Eigenvalues (VARMA) & $\lambda_{\{i=1, \ldots, 6\}}$ & $\max \left|\lambda_{i}\right|<1$ \\
Covariances & $\sum_{y y}, \Sigma_{c c}, \Sigma_{h h}, \Sigma_{y c}, \Sigma_{y h}, \Sigma_{c h}$ & $\Sigma$ is + is $+\lambda_{i} \mid<1$ \\
Model semi-definite & $\frac{(\eta-\beta(1-\theta)(1-\delta))}{(\beta \eta \theta)}>1$ and $\frac{(\eta \theta)}{(\eta-\beta(1-\theta)(1-\delta))}<1$ \\
\hline
\end{tabular}

Finally, note that following Gelman et al. (1996) and FernándezVillaverde and Rubio-Ramírez (2004) we designed the proposal covariance matrix such that the acceptance rate was between 20-40 percent. For the results reported in Table 2 below, the acceptance rates were 34.51, 27.61 and 39.36 percent for the $\operatorname{AR}(1), \operatorname{VAR}(1)$ and $\operatorname{VARMA}(1,1)$ models respectively.

\section{Estimation results}

In this section we start by presenting the first two moments of the posterior parameter distributions and numerical standard errors for each parameter. ${ }^{9}$ We then report information pertaining to the relative fit of the competing models. This is achieved, first, by application of the marginal likelihood ratio test and second by comparisons of actual data on output, consumption, investment and hours with the models' predictions.

\subsection{Posterior distributions of parameters}

Table 2 summarizes the parameter distributions along with the posterior distributions of the eigenvalues and the covariances of all three models. The table contains the mean and standard deviation of the posterior distributions

\footnotetext{
${ }^{9}$ These models are all estimated over the full sample period, 1948:1-2002:2. Given evidence of multiple modes in some of the parameter distributions, even when the number of simulations is increased to $1,000,000$, we return to the issue of parameter stability below.
} 
of the parameters along with a measure of estimation accuracy based on numerical standard errors, NSE (see, e.g. Geweke (1992)). ${ }^{10}$

It is first useful to contextualize the size of the means of the structural parameters reported in Table 2 with the estimated parameters in Ireland (2004). For example, conditioning of a fixed value of $\beta=0.99$ and $\delta=$ 0.025 , Ireland estimated the following values using maximum likelihood: $[\gamma=$ $\left.0.0045 ; \rho=0.9987 ; A=5.1847 ; \theta=0.2292 ; \eta=1.0051 ; \sigma_{e}=0.0056\right]$. While it reassuring that our results are so similar to Ireland's, it is not entirely unexpected given that we estimate the same model with the same data.

It is next of interest to note that our estimates of the structural parameters remain very stable across the three models with the most relative movement occurring for the trend, $\eta$, and the variance of technology parameters, $\sigma_{e}$. This stability is again perhaps not surprising since there is no change in the RBC part of the model across the three estimations. In contrast, we see substantial change in the modes of the eigenvalues in the AR/VAR/VARMA matrices and the covariances as we move from the restrictive to the general model of the errors. It remains to be seen, in the next subsection, if accounting for the movements and co-movements of the errors in this way implies a better fit for the $\operatorname{VARMA}(1,1)$ model.

If we now turn to the spread of these distributions, it is again informative to present our results in the context of the literature. Here we cannot rely on the Ireland study given the different approaches we apply to estimation. However, the recent study by Fernández-Villaverde and Rubio-Ramírez (2005) includes a Bayesian estimation of a linearized RBC model and reports standard deviations that are roughly the same order of magnitude but generally larger. The fact that our distributions are even tighter is most likely due to the fact that we explicitly model the errors with varying degress of structure whereas they employ a simple additive error term in their measurement system. But, of course, some of these dissimilarities could also be due to differences, for example, in model structure, data used, de-trending methods, etc. ${ }^{11}$

Finally, examination of the numerical standard errors as a share of the means of the posteriors reveals that our estimates are generally quite precise. The most accurate block appears to be the structural one, followed by the covariance and eigenvalue blocks. The largest values of $\left(\frac{N S E}{\left|\bar{\psi}_{i}\right|} \times 100\right)$ for

\footnotetext{
${ }^{10}$ Note that the ratio reported in the Table 2 is in percent terms, i.e. $\frac{N S E}{\left|\bar{\psi}_{i}\right|} \times 100$.

${ }^{11}$ As in Ireland (2004), we estimate and detrend simultaneously, since $\eta$ is part of the parameter vector (see Section 2.4).
} 
Table 2: Posterior distributions of parameters, $\boldsymbol{\psi}$

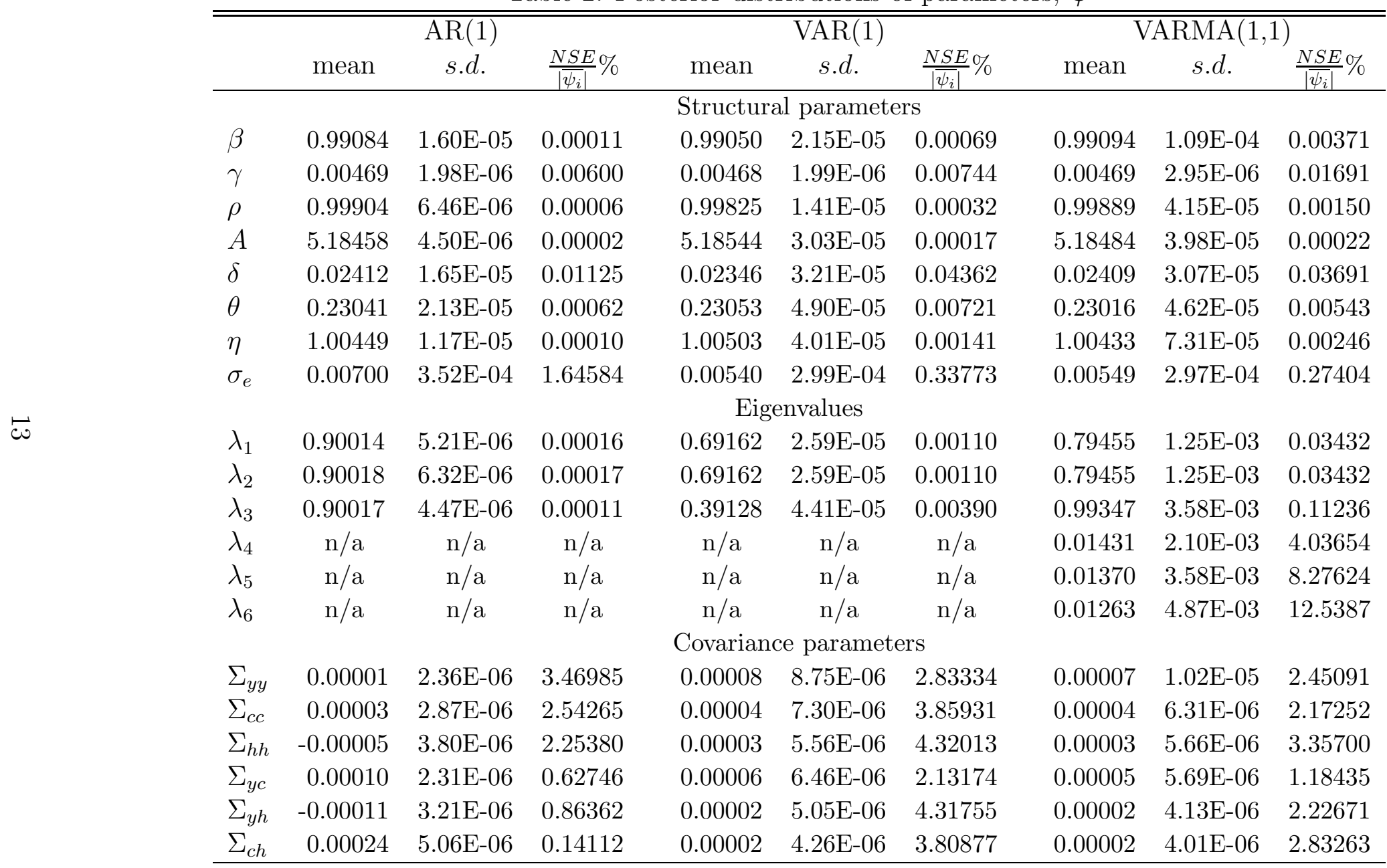


each block respectively, are $0.27,3.36$ and 12.54 percent. $^{12}$

\subsection{Model comparison}

To compare the fit of alternative specifications for the error block, we follow Chib and Jeliazkov (2001) and calculate Bayes factors based on marginal likelihoods obtained from the simulated parameter realizations. Let $M_{j}, j=$ 1,2,3 denote the $\operatorname{AR}(1), \operatorname{VAR}(1)$, and $\operatorname{VARMA}(1,1)$ models respectively. The Bayes factors for comparing model $j$ and $k$ are given by the ratio of the two marginal likelihoods for $M_{j}$ and $M_{k}$,

$$
B F_{j k}=\frac{p\left(\mathbf{y} \mid M_{j}\right)}{p\left(\mathbf{y} \mid M_{k}\right)}
$$

The marginal likelihood identity follows from Bayes' formula:

$$
\begin{aligned}
p\left(\boldsymbol{\psi}_{j} \mid \mathbf{y}, M_{j}\right) & =\frac{p\left(\mathbf{y} \mid \boldsymbol{\psi}_{j}, M_{j}\right) p\left(\boldsymbol{\psi}_{j} \mid M_{j}\right)}{p\left(\mathbf{y} \mid M_{j}\right)} \\
p\left(\mathbf{y} \mid M_{j}\right) & =\frac{p\left(\mathbf{y} \mid \boldsymbol{\psi}_{j}, M_{j}\right) p\left(\boldsymbol{\psi}_{j} \mid M_{j}\right)}{p\left(\boldsymbol{\psi}_{j} \mid \mathbf{y}, M_{j}\right)}, j=1,2,3 .
\end{aligned}
$$

Calculated at e.g. the mean of the posterior density $\boldsymbol{\psi}_{j}^{\star}$, the logarithm of the marginal likelihood is

$$
\ln p\left(\mathbf{y} \mid M_{j}\right)=\ln p\left(\mathbf{y} \mid \boldsymbol{\psi}_{j}^{\star}, M_{j}\right)+\ln p\left(\boldsymbol{\psi}^{\star} \mid M_{j}\right)-\ln p\left(\boldsymbol{\psi}_{j}^{\star} \mid \mathbf{y}, M_{j}\right) .
$$

To compute the marginal likelihood, we need to find $p\left(\boldsymbol{\psi}_{j}^{\star} \mid \mathbf{y}, M_{j}\right)$. We next denote the candidate generating density for the move from $\boldsymbol{\psi}$ to $\boldsymbol{\psi}^{\prime}$ as $q\left(\boldsymbol{\psi}^{\prime} \mid \boldsymbol{\psi}, \mathbf{y}\right)$. The acceptance probability is given as

$$
\begin{aligned}
p\left(\boldsymbol{\psi}^{\star} \mid \boldsymbol{\psi}, \mathbf{y}\right) & =\alpha\left(\boldsymbol{\psi}^{\star} \mid \boldsymbol{\psi}, \mathbf{y}\right) q\left(\boldsymbol{\psi}^{\star} \mid \boldsymbol{\psi}, \mathbf{y}\right) \\
\alpha\left(\boldsymbol{\psi}^{\star} \mid \boldsymbol{\psi}, \mathbf{y}\right) & =\min \left(1, \frac{f\left(\mathbf{y} \mid \boldsymbol{\psi}^{\star}\right) p\left(\boldsymbol{\psi}^{\star}\right)}{f(\mathbf{y} \mid \boldsymbol{\psi}) p(\boldsymbol{\psi})} \frac{q\left(\boldsymbol{\psi} \mid \boldsymbol{\psi}^{\star}, \mathbf{y}\right)}{q\left(\boldsymbol{\psi}^{\star} \mid \boldsymbol{\psi}, \mathbf{y}\right)}\right) .
\end{aligned}
$$

Integrating

$$
p\left(\boldsymbol{\psi}^{\star} \mid \boldsymbol{\psi}, \mathbf{y}\right) p(\boldsymbol{\psi} \mid \mathbf{y})=p\left(\boldsymbol{\psi} \mid \boldsymbol{\psi}^{\star}, \mathbf{y}\right) p\left(\boldsymbol{\psi}^{\star} \mid \mathbf{y}\right)
$$

over $\boldsymbol{\psi}$, we obtain

$$
p\left(\boldsymbol{\psi}^{\star} \mid \mathbf{y}\right)=\frac{\int \alpha\left(\boldsymbol{\psi}^{\star} \mid \boldsymbol{\psi}, \mathbf{y}\right) q\left(\boldsymbol{\psi}^{\star} \mid \boldsymbol{\psi}, \mathbf{y}\right) p(\boldsymbol{\psi} \mid \mathbf{y}) \mathrm{d} \boldsymbol{\psi}}{\int \alpha\left(\boldsymbol{\psi} \mid \boldsymbol{\psi}^{\star}, \mathbf{y}\right) q\left(\boldsymbol{\psi} \mid \boldsymbol{\psi}^{\star}, \mathbf{y}\right) \mathrm{d} \boldsymbol{\psi}}
$$

\footnotetext{
${ }^{12}$ Note that our most inaccurate estimate is of a similar magnitude to others described in the literature, e.g. Dejong et al. (2000) reports a value of 11 percent for their least accurate estimate.
} 
which is a ratio of two expected values

$$
p\left(\boldsymbol{\psi}^{\star} \mid \mathbf{y}\right)=\frac{\mathrm{E}\left(\alpha\left(\boldsymbol{\psi}^{\star} \mid \boldsymbol{\psi}, \mathbf{y}\right) q\left(\boldsymbol{\psi}^{\star} \mid \boldsymbol{\psi}, \mathbf{y}\right)\right)}{\mathrm{E}\left(\alpha\left(\boldsymbol{\psi} \mid \boldsymbol{\psi}^{\star}, \mathbf{y}\right)\right)}
$$

that can be estimated as

$$
\hat{p}\left(\boldsymbol{\psi}^{\star} \mid \mathbf{y}\right)=\frac{\frac{1}{S} \sum_{s=1}^{S} \alpha\left(\boldsymbol{\psi}^{\star} \mid \boldsymbol{\psi}_{s}, \mathbf{y}\right) q\left(\boldsymbol{\psi}^{\star} \mid \boldsymbol{\psi}_{s}, \mathbf{y}\right)}{\frac{1}{J} \sum_{j=1}^{J} \alpha\left(\boldsymbol{\psi}_{j} \mid \boldsymbol{\psi}^{\star}, \mathbf{y}\right)}
$$

where $\boldsymbol{\psi}_{s}$ are realizations of $\boldsymbol{\psi}$ from the posterior distribution and $\boldsymbol{\psi}_{j}$ are draws from the candidate generating density conditional on $\boldsymbol{\psi}^{\star}$. Substituting $\hat{p}\left(\boldsymbol{\psi}^{\star} \mid \mathbf{y}\right)$ into the logarithm of the marginal likelihood identity gives

$$
\ln \hat{p}\left(\mathbf{y} \mid M_{j}\right)=\ln p\left(\mathbf{y} \mid \boldsymbol{\psi}_{j}^{\star}, M_{j}\right)+\ln p\left(\boldsymbol{\psi}^{\star} \mid M_{j}\right)-\ln \hat{p}\left(\boldsymbol{\psi}_{j}^{\star} \mid \mathbf{y}, M_{j}\right) .
$$

Table 3 below reports the results of the logmarginal likelihood difference test, using (21) and (28), for our three models of interest. An intuitive interpretation is provided by Fernández-Villaverde and Rubio-Ramírez (2005, p. 907-908) who state "Another way to think about the marginal likelihood is as a measure of the ability of the model to forecast within sample." To aid the interpretation regarding the size of the gains in relative fit, FernándezVillaverde and Rubio-Ramírez (2005, p. 902) further remark "A good way to read this number is to use Jeffreys' (1961) rule: if one hypothesis is more than 100 times more likely than the other, the evidence is decisive in its favour. This translates into differences in logmarginal likelihoods of 4.6 or higher". Given that all of the differences reported in Table 3 are greater than 4.6 , we can conclude that the $\operatorname{VARMA}(1,1)$ is far more likely to accurately predict the historical data than the $\operatorname{VAR}(1)$ and $\operatorname{AR}(1)$ alternatives.

Table 3: Differences in

logmarginal likelihoods

\begin{tabular}{ccc}
\hline \hline & VAR(1) & VARMA(1,1) \\
\hline $\operatorname{AR}(1)$ & 210.79 & 234.20 \\
$\operatorname{VAR}(1)$ & n/a & 23.40 \\
\hline
\end{tabular}

\subsection{RBC model versus error system fit}

In light of the above results regarding overall model fit, it is also informative to examine the models' ability to predict the individual measured series under consideration. Moreover since a hybrid estimation approach is employed it is also useful to decompose the predictions provided by the RBC versus the measurement/specification error block. 
To implement this, first recall the $\operatorname{VAR}(1)$ measurement error setup in equation (14). ${ }^{13}$ By simulating smoothed states $\boldsymbol{\alpha}_{t}$ and $\boldsymbol{\eta}_{t}$ using the posterior means of the model parameters, we arrive at data predictions from the RBC and the error blocks of the model. ${ }^{14}$ Next, for each model (AR(1), VAR(1) and $\operatorname{VARMA}(1,1))$ and each component part (RBC and error system), we simulate 1000 replications of the technology shock and the shocks to the error system, respectively. To obtain the predictions of the RBC block, the measurement equation in (14) becomes

$$
\hat{\mathbf{y}}_{t}^{R B C}=\mathbf{Z} \boldsymbol{\alpha}_{t}
$$

with the predictions for the error system given by

$$
\hat{\mathbf{y}}_{t}^{E S}=\boldsymbol{\eta}_{t}
$$

where $\hat{\mathbf{y}}_{t}^{\text {data }}=\hat{\mathbf{y}}_{t}^{R B C}+\hat{\mathbf{y}}_{t}^{E S}$.

The within-sample forecasts of (29) and (30) for the measured data across the three models are contained in Figure 1 below which plots the actual log deviations for the measured variables against the predictions of the RBC versus the error blocks of the model. These provide an idea of the relative ability of the competing blocks to predict within-sample movements of the data. The first point to note in Figure 1 is that as we move from the $\operatorname{AR}(1)$ model of the errors to the more general models, the fit of the RBC model worsens as the error models take on a more prominent predictive role. It is also interesting to note that the RBC model does a poor job at predicting hours for all models, especially from around 1980.

Thus it appears that ignoring the dynamic interactions in the errors leads to a overly optimistic view regarding the ability of the RBC model to replicate the logged deviations data (except of course for hours). It remains to be seen below how the more general models of the errors affect the RBC model's ability to explain the observed variation in each of these aggregates.

\footnotetext{
${ }^{13}$ The procedure for the $\operatorname{VARMA}(1,1)$ measurement error is equivalent.

${ }^{14}$ The smoothing step of the Kalman filter starts with the last updated state $\mathbf{a}_{T}$ and the last covariance matrix $\mathbf{P}_{T}$, and runs the Kalman filter backwards, as described in Hamilton (1994, p. 394-397) or Harvey (1992, p. 154-155).
} 


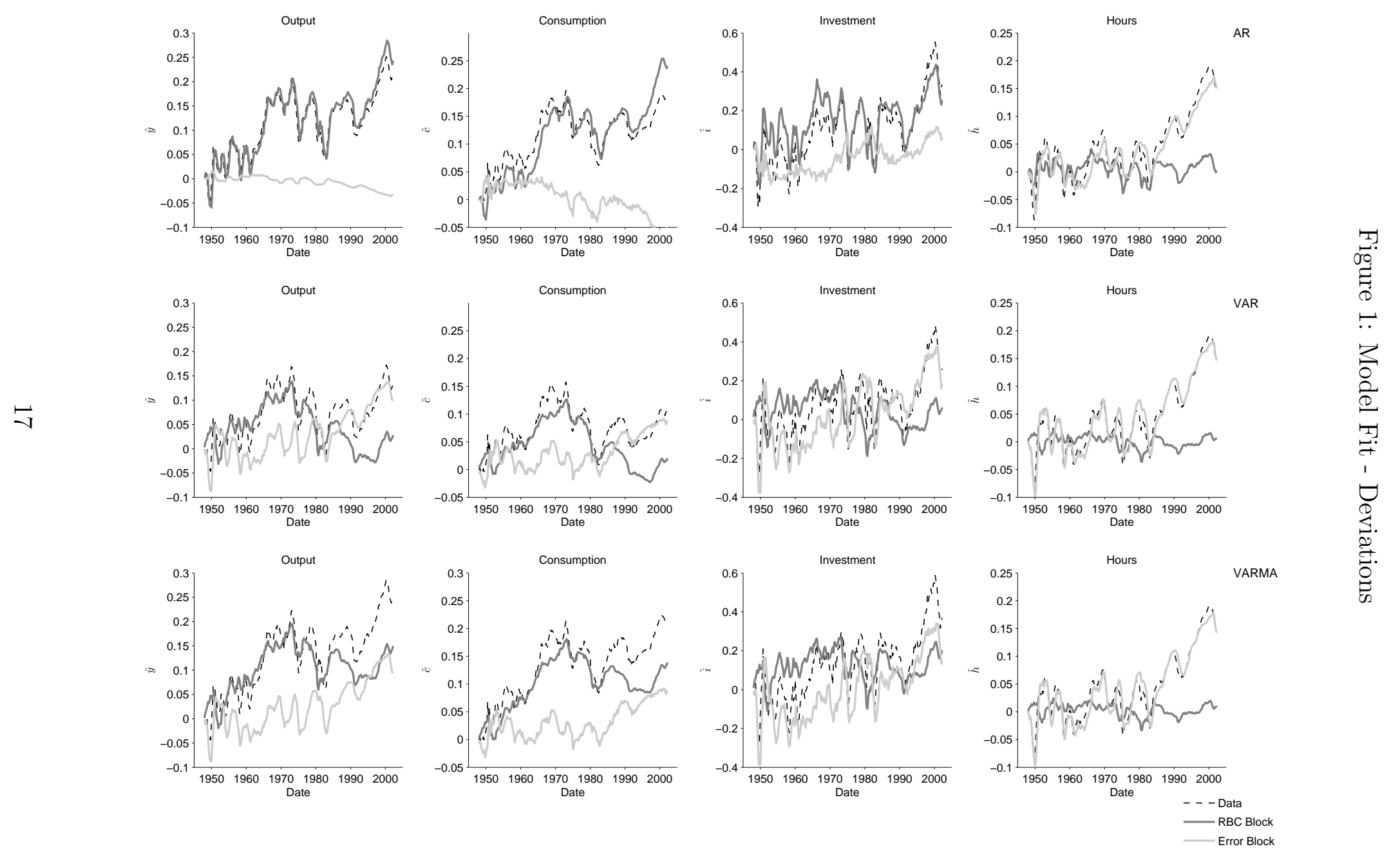




\subsection{Productivity slowdown in the $1970 \mathrm{~s}$}

Another means of assessing the ability of the estimated models to describe important features in the data, is to check if the RBC models' estimates of unobserved productivity, $A_{t}$, capture the much heralded slowdown in US productivity post 1972 through 1995 (see e.g. Ireland and Schuh (2008), Nordhaus (2004), Ireland (2001) and Gordon (2000)). Following Ireland (2001), to undertake this comparison, we compute the standard Solow residual, Solow $=\left(\frac{1}{1-\theta}\right) \ln \left(Y_{t}\right)-\left(\frac{\theta}{1-\theta}\right) \ln \left(K_{t}\right)-\ln H_{t}$ using: (i) data for output ${ }^{15}$, investment and hours; (ii) equation (3) to obtain $K_{t}$; and (iii) estimates of $\theta$ and $\delta .^{16}$ Finally, it is interesting to note that the simple correlation of the models' (annualized) Solow residual with the Bureau of Labor Statistics (BLS) multi-factor productivity for private nonfarm business $(2000=100)$ is approximately 0.80 .

Figure 2: Productivity Slowdown in the 1970s

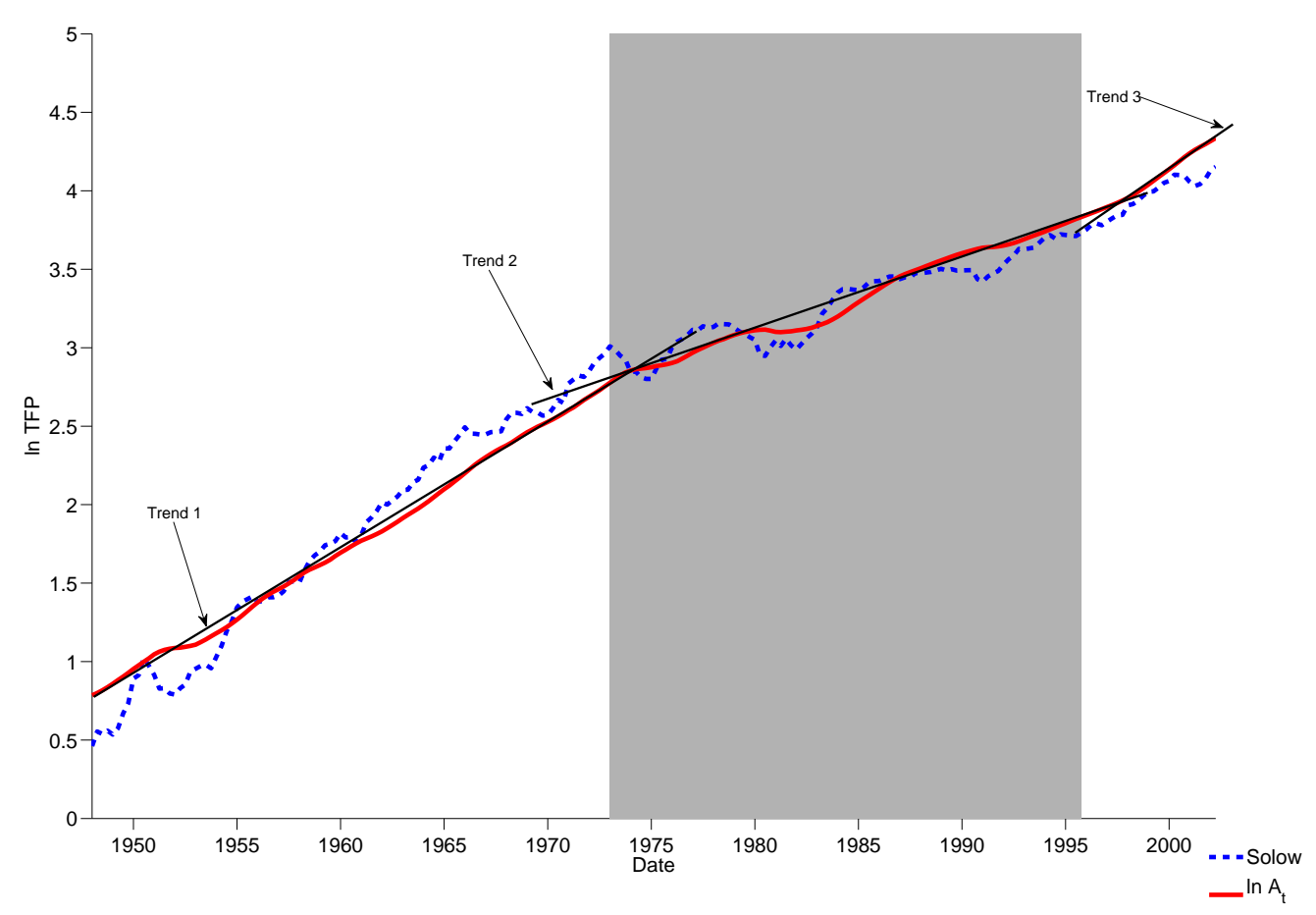

Figure 2 above plots the model based estimate of $\ln \left(A_{t}\right)$ using the

\footnotetext{
${ }^{15}$ Note that, as in Ireland (2001), output is the sum of consumption and investment.

${ }^{16}$ For (iii) we use the estimates from each of the 3 -models.
} 
$\operatorname{VARMA}(1,1)$ model against the Solow residual. ${ }^{17}$ The gray shaded area corresponds with the time period generally associated with the productivity slowdown between the early 1970s to the mid-1990s. In addition to these plots we also draw three trend lines through the estimates of the hybrid $\mathrm{RBC}$ model to show the extent to which the models predictions capture the productivity slowdown. This figure shows that while the model is able to approximately match the long swings in the Solow residual, its has a harder time matching its cyclical variability. Thus, despite the model's predictions for productivity being somewhat smoother than the Solow residual, the hybrid RBC model does appear to do a reasonable job at picking up the trend changes in TFP much documented in the productivity literature. ${ }^{18}$

\section{Explanatory power of the RBC model}

We next turn to an assessment of the RBC model's ability to explain the observed variation in the measured data. To this end, we first undertake forecast error decompositions (FEDs) which allow us to split the contemporaneous and the $k$-step-ahead forecast error variances of the measured variables into the portions explained by shocks to technology and shocks to the error system. The latter, as Ireland (2004, p. 1213) points out, “...pick up the combined effects of shocks, including monetary and fiscal policy shocks, not present in the real business cycle model". Thus, in the context of the hybrid setup, the RBC model faces a more difficult task since more shocks have been added to explain the variation in the measured data. In the light of the objectives of this paper and the findings of the last section, we are especially interested to discover the extent to which the RBC model's predictions, based on calibration and other estimation studies, are robust to the inclusion of these new shocks. Finally we employ multivariate spectral methods to further evaluate the explanatory power of the RBC model at alternative business cycle frequencies. ${ }^{19}$ Analogous to the FEDs, we will calculate the proportion of the variance of our measured data explained by the variance of the technology shocks.

\footnotetext{
${ }^{17}$ Since the model based estimates of $\ln \left(A_{t}\right)$ are quite similar, we only present the model with VARMA(1,1) errors here.

${ }^{18}$ Also note that a similar picture emerges when the annualized model estimates are compared with the BLS annual estimates of multifactor productivity.

${ }^{19}$ See Watson (1993) for a univariate spectral analysis of the cyclical properties of a calibrated stochastic RBC model.
} 


\subsection{Forecast error decompositions}

Figures 3-6 report the share of the forecast error for output, consumption, investment and hours explained by the technology shock (see left axis) and the error system (see right axis). All of the measured data are in terms of log-deviations from trend. The figures contain the decompositions for each of the 3 -estimated models at forecast horizons $k=\{0,1,4,8,12,20,40, \infty\}$ as well as information pertaining to their distributions. ${ }^{20}$ For example, the box plots show the: (i) median; (ii) inter-quartile range; and (iii) extreme values at each $k$.

The first point to note in these figures is that $\mathrm{AR}(1)$ model, with the exception of hours, always attributes a more dominate role to the RBC model in explaining the variance of output and its components than the other two models. Moreover, the uncertainty associated with these estimates appears to be quite small based on the size of the inter-quartile ranges. As expected, as we move to the more complex models of the errors the explanatory power of the RBC model generally decreases. For example, the median unconditional variance explained by the $\operatorname{AR}(1), \operatorname{VAR}(1)$ and $\operatorname{VARMA}(1,1)$ models respectively is approximately: $(99 \%, 82 \%, 60 \%)$ for output; $(97 \%, 92 \%, 68 \%)$ for consumption; $(89 \%, 38 \%, 35 \%)$ for investment; and $(10 \%, 0.01 \%, 0.001 \%)$ for hours.

Next note that the U-shaped pattern of the FEDs for output and investment in the $\operatorname{VAR}(1)$ and $\operatorname{VARMA}(1,1)$ cases is similar to the findings in Ireland (2004). In other words, the RBC model does a relatively better job at explaining output fluctuations at short- and long-forecast horizons. Also, the general pattern of the consumption and hours FEDs in the VAR(1) and VARMA $(1,1)$ models are similar to those reported in Ireland (2004). That is, the RBC model's explanatory power increases (decreases) as the consumption (hours) horizon increases.

In the case of hours, it is further interesting to note how the more general hybrid RBC models does better than the AR(1) model when explaining hours fluctuations at short horizons. Again, Ireland (2004, p. 1215) finds a similar result and argues that "This result is encouraging, since it suggests that the real business cycle model still has some success in tracking quarter-to-quarter movements in aggregate employment, even if it fares less well in explaining movements over longer horizons".

To place the size of the FEDs in context it is useful to take into account that they are similar to $R^{2} s$ in simple regression analysis and that logdeviations data are employed when calculating them. In simple regression

\footnotetext{
${ }^{20}$ Note that both the forecast error and spectral decomposition (see below) are posterior distributions and based on the draws we keep from each of the chains.
} 
Figure 3: Forecast Error Decomposition, Output

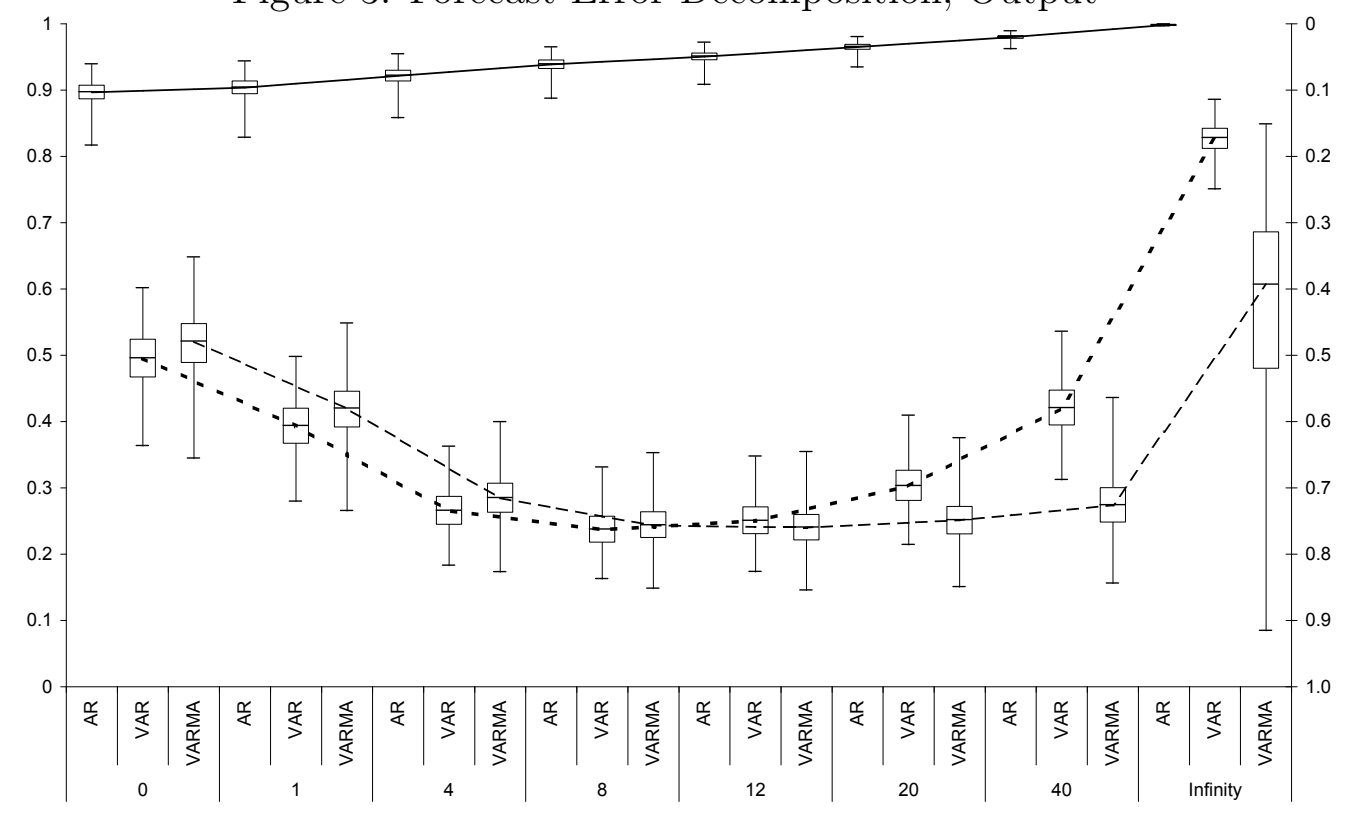

Figure 4: Forecast Error Decomposition, Consumption

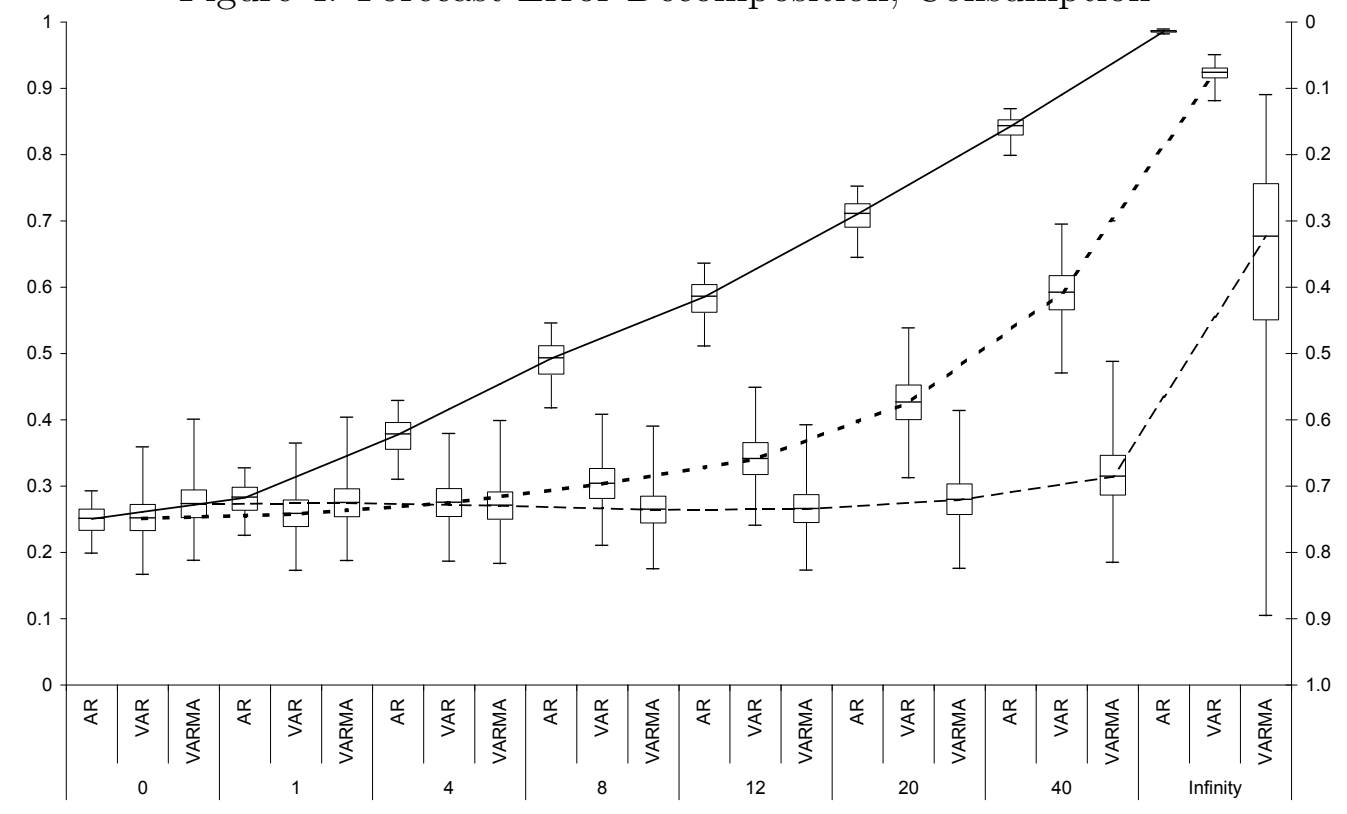


Figure 5: Forecast Error Decomposition, Investment

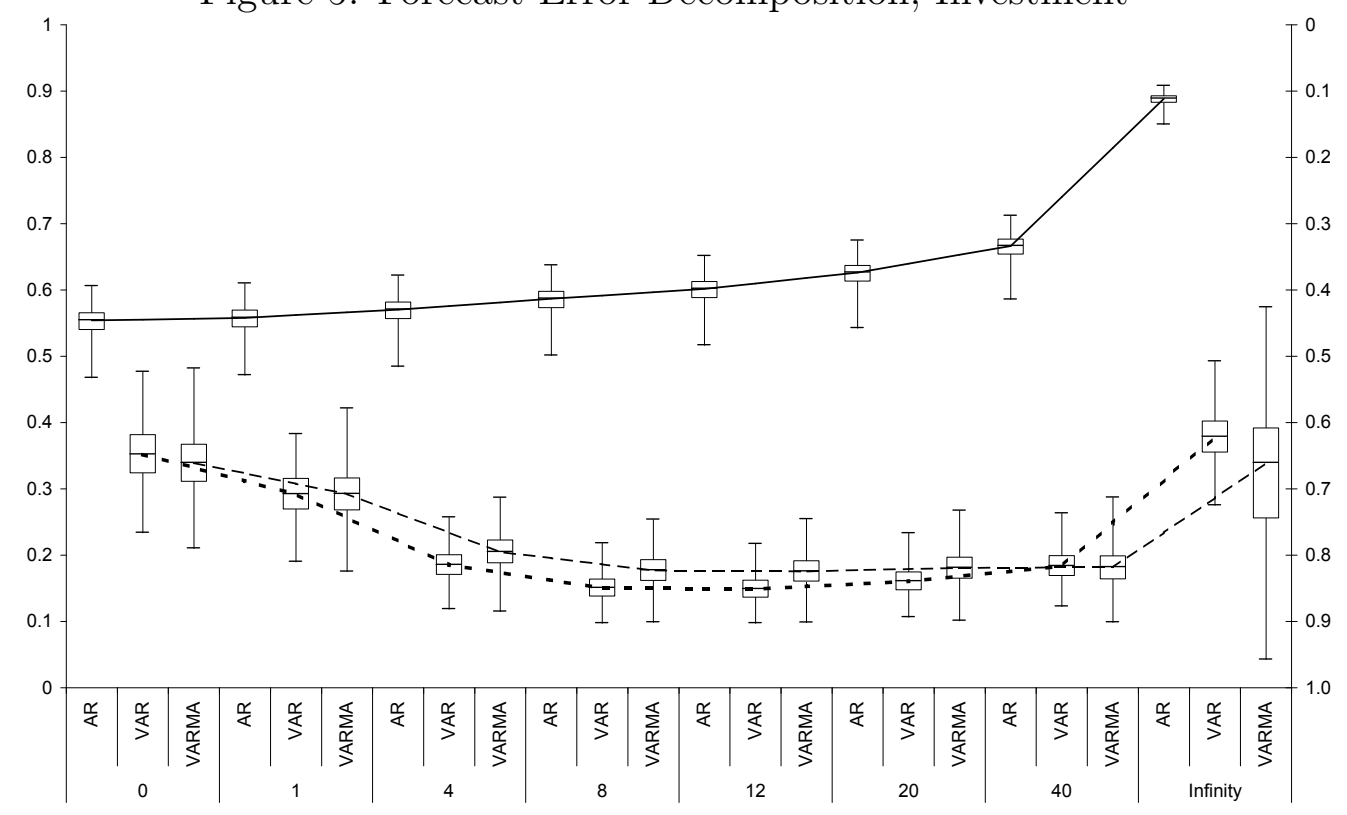

Figure 6: Forecast Error Decomposition, Hours

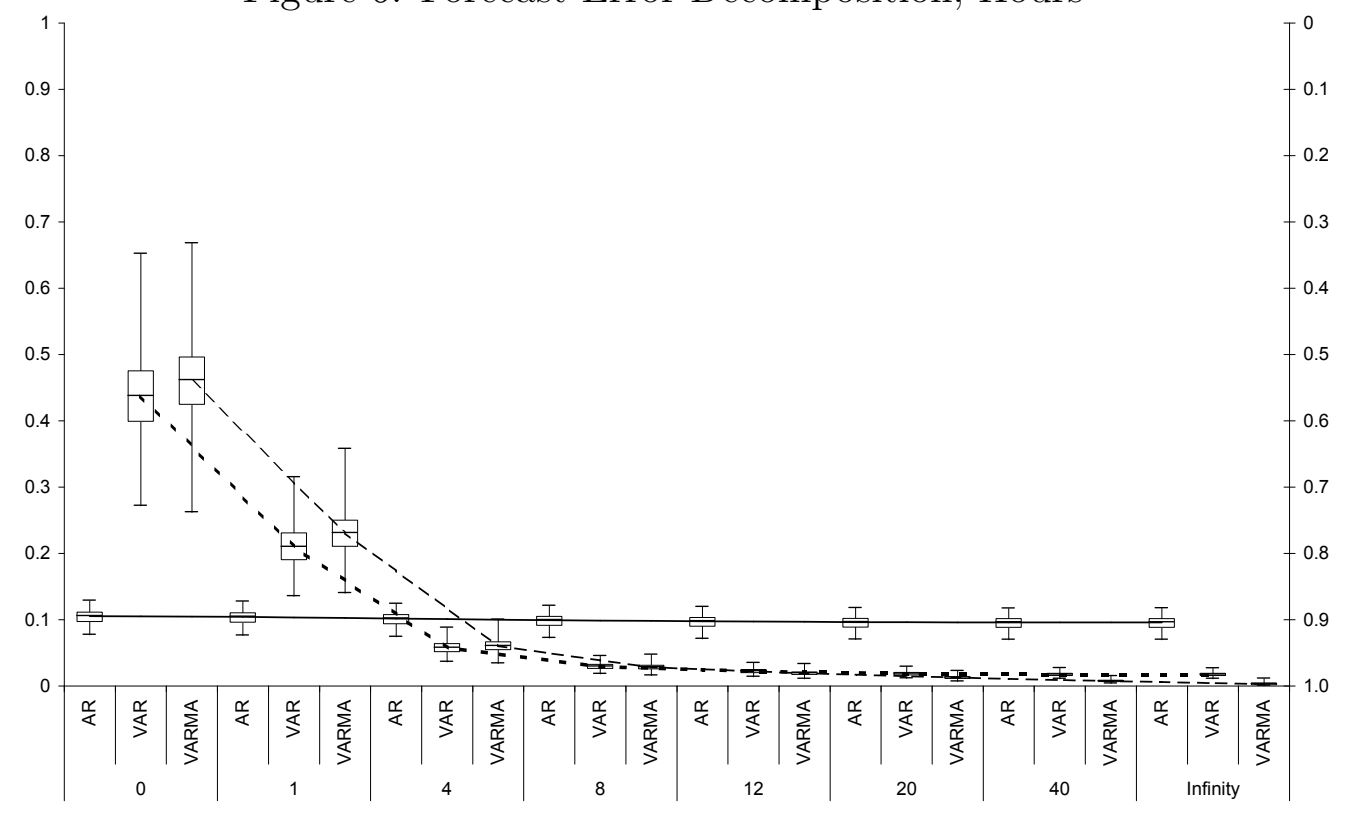


analysis, using de-trended data, if the proportion of total variance explained is roughly $40 \%$ or greater then, ceteris paribus, this would be considered a reasonably good fit. Thus, it appears that the $\mathrm{RBC}$ model, even in the presence of $\operatorname{VARMA}(1,1)$ errors is still capable of explaining a non-trivial share of aggregate fluctuations. Moreover, given that the various distributions of the FEDs are generally quite concentrated, there appears to be much more room for optimism regarding the degree of uncertainty associated with the explanatory power of the RBC model than is expressed by some authors cited in the introduction.

\subsection{Spectral decompositions}

To next compare the explanatory power of the three RBC models over different business cycle ranges, we use the means of the posterior parameter distributions and the state space representation to calculate the spectral density matrices. Because of the autoregressive structure, it is straightforward to calculate the spectral density matrix for the transition equation system: ${ }^{21}$

$$
\begin{aligned}
\widetilde{\boldsymbol{\alpha}}_{t} & =\widetilde{\mathbf{T}} \widetilde{\boldsymbol{\alpha}}_{t-1}+\boldsymbol{\zeta}_{t}, \quad \boldsymbol{\zeta}_{t} \sim N(\mathbf{0}, \boldsymbol{\Sigma}) \\
\mathbf{F}_{\widetilde{\alpha}}(\omega) & =\frac{1}{2 \pi} \widetilde{\mathbf{T}}(\omega)^{-1} \boldsymbol{\Sigma} \widetilde{\mathbf{T}}(\omega)^{-\star} ; \omega \in[-\pi, \pi] .
\end{aligned}
$$

where $\widetilde{\mathbf{T}}(\omega)$ is the Fourier transform of the matrix lag polynomial $\widetilde{\mathbf{T}}(L)=$ $\mathbf{I}-\widetilde{\mathbf{T}} L .^{22}$ Once the matrix $\mathbf{F}_{\widetilde{\alpha}}(\omega)$ is calculated, the measurement equation can be used to obtain the spectral density matrix for $\mathbf{y}_{t}$ and $\widetilde{\boldsymbol{\alpha}}_{t}, t=1, \ldots, T$ :

$$
\mathbf{F}_{y, c, h, \widetilde{\alpha}}(\omega)=\widetilde{\mathbf{Z}} \mathbf{F}_{\widetilde{\alpha}}(\omega) \widetilde{\mathbf{Z}}^{\prime} ; \quad \omega \in[-\pi, \pi]
$$

Since the elements of the vector $\mathbf{y}_{t}$ are output, consumption, and hours, the spectral density matrix containing also investment can be derived as

$$
\mathbf{F}_{i, y, c, h, \widetilde{\alpha}}(\omega)=\left(\begin{array}{ccc}
\mathbf{X} & & \mathbf{0} \\
& \mathbf{I} &
\end{array}\right) \mathbf{F}_{y, c, h, \widetilde{\alpha}}(\omega)\left(\begin{array}{ccc}
\mathbf{X} & & \mathbf{0} \\
& \mathbf{I}
\end{array}\right)^{\prime} ; \omega \in[-\pi, \pi],
$$

where

$$
\mathbf{X}=\left(\begin{array}{ccc}
1 & 0 & 0 \\
\frac{\bar{y}}{\bar{l}} & -\frac{\bar{c}}{\overline{\bar{l}}} & 0 \\
0 & 1 & 0 \\
0 & 0 & 1
\end{array}\right)
$$

\footnotetext{
${ }^{21}$ See e.g. Priestley (1981) and Hamilton (1994, Ch. 6) for a textbook treatment of spectral analysis.

${ }^{22} L$ is the backshift operator; the superscript ' $\star$ ' denotes the complex conjugate transpose.
} 
The measure presented in Table 4 below is "explained variance", derived from squared coherency $(s c)$. Squared coherency assesses the degree of linear relationship between cyclical components of two series $X_{t}$ and $Y_{t}$, frequency by frequency. It is defined as

$$
s c(\omega)=\frac{\left|f_{y x}(\omega)\right|^{2}}{f_{x}(\omega) f_{y}(\omega)} ; \quad 0 \leq s c(\omega) \leq 1,
$$

where $f_{x}(\omega)$ is the spectrum of the series $X_{t}$ from the diagonal of the spectral density matrix $\mathbf{F}(\omega)$, and $f_{y x}(\omega)$ is the cross-spectrum for $Y_{t}$ and $X_{t}$, the relevant off-diagonal element of $\mathbf{F}(\omega)$. Using this expression, we can decompose $f_{y}(\omega)$ into and explained and an unexplained part. Integrating it over the frequency band $[-\pi, \pi]$ gives

$$
\underbrace{\int_{-\pi}^{\pi} f_{y}(\omega) d \omega}_{\gamma_{y}(0)}=\underbrace{\int_{-\pi}^{\pi} s c(\omega) f_{y}(\omega) d \omega}_{\text {"explained"variance }}+\int_{-\pi}^{\pi} f_{u}(\omega) d \omega .
$$

The first term on the right in equation (33) is the product of squared coherency between $X_{t}$ and $Y_{t}$ and the spectrum of $Y_{t}$; and the second term is white noise. This equality holds for every frequency band $\left[\omega_{1}, \omega_{2}\right]$. Comparing the area under the spectrum of the explained component to the area under $Y$ 's (i.e. output, consumption, investment and hours) spectrum in a frequency interval $\left[\omega_{1}, \omega_{2}\right]$ yields a measure of the explanatory power of $X$ (i.e. technology shocks), analogous to a partial $R^{2}$ in the time domain. ${ }^{23}$

Table 4 contains the results of the spectral decompositions, i.e. the means and standard deviations (in brackets) of the posterior distribution of the spectral measures. These measures are reported over the high and low frequency ranges (i.e. 2-quarters to 3-years and 10 to infinity years respectively) and the classical business cycle ranges (i.e. $3-5,5-7$ and $7-10$ years). ${ }^{24}$

\footnotetext{
${ }^{23}$ See A'Hearn and Woitek (2001) for a detailed discussion.

${ }^{24}$ Note that the results of a univariate spectral analysis are consistent with the findings of Watson (2003). In particular, we find that the RBC model, irrespective of the error model employed, does a very good job at matching the low frequency movements in the data for output and its components. For high frequency movements, the model spectra for output provide the relatively best match to the data spectra. In contrast, the model spectra are significantly different from the data spectra for the traditional business cycle ranges for all measured variables (i.e. $y, c, i, h)$. Further details relating to the univariate results are available upon request from the authors.
} 
Table 4: Spectral decompositions

(\% variance in $y, c, i, h$ explained by technology shocks)

\begin{tabular}{|c|c|c|c|c|c|c|}
\hline & (years) & $\begin{array}{l}\text { high } \\
\text { freq. } \\
0.5-3\end{array}$ & $\begin{array}{c}\text { short } \\
\text { cycle } \\
3-5\end{array}$ & $\begin{array}{c}\text { med. } \\
\text { cycle } \\
5-7\end{array}$ & $\begin{array}{c}\text { long } \\
\text { cycle } \\
7-10\end{array}$ & $\begin{array}{c}\text { low } \\
\text { freq. } \\
10-\infty\end{array}$ \\
\hline \multirow{3}{*}{$y$} & $\mathrm{AR}(1)$ & $\begin{array}{c}0.891 \\
(0.018)\end{array}$ & $\begin{array}{c}0.893 \\
(0.018)\end{array}$ & $\begin{array}{c}0.898 \\
(0.017)\end{array}$ & $\begin{array}{c}0.905 \\
(0.016)\end{array}$ & $\begin{array}{c}0.999 \\
(0.000)\end{array}$ \\
\hline & $\operatorname{VAR}(1)$ & $\begin{array}{c}0.281 \\
(0.030)\end{array}$ & $\begin{array}{c}0.190 \\
(0.023)\end{array}$ & $\begin{array}{c}0.139 \\
(0.018)\end{array}$ & $\begin{array}{c}0.132 \\
(0.017)\end{array}$ & $\begin{array}{c}0.863 \\
(0.018)\end{array}$ \\
\hline & $(1,1)$ & $\begin{array}{c}0.311 \\
(0.034)\end{array}$ & $\begin{array}{c}0.218 \\
(0.027)\end{array}$ & $\begin{array}{c}0.177 \\
(0.023)\end{array}$ & $\begin{array}{c}0.180 \\
(0.023)\end{array}$ & $\begin{array}{c}0.645 \\
(0.180)\end{array}$ \\
\hline \multirow{3}{*}{$c$} & $\mathrm{AR}($ & $\begin{array}{c}0.238 \\
((0.018)\end{array}$ & $\begin{array}{c}0.255 \\
(0.019)\end{array}$ & $\begin{array}{c}0.294 \\
(0.021)\end{array}$ & $\begin{array}{c}0.355 \\
(0.023)\end{array}$ & $\begin{array}{c}0.992 \\
(0.001)\end{array}$ \\
\hline & $\operatorname{VAR}(1)$ & $\begin{array}{c}0.234 \\
(0.027)\end{array}$ & $\begin{array}{c}0.224 \\
(0.026)\end{array}$ & $\begin{array}{c}0.202 \\
(0.025)\end{array}$ & $\begin{array}{c}0.198 \\
(0.024)\end{array}$ & $\begin{array}{c}0.936 \\
(0.009)\end{array}$ \\
\hline & $\operatorname{VARMA}(1,1)$ & $\begin{array}{c}0.266 \\
(0.030)\end{array}$ & $\begin{array}{c}0.259 \\
(0.029)\end{array}$ & $\begin{array}{c}0.231 \\
(0.027)\end{array}$ & $\begin{array}{c}0.220 \\
(0.027)\end{array}$ & $\begin{array}{c}0.709 \\
(0.184)\end{array}$ \\
\hline \multirow{3}{*}{$i$} & $\operatorname{AR}(1)$ & $\begin{array}{c}0.546 \\
(0.023)\end{array}$ & $\begin{array}{c}0.544 \\
(0.023)\end{array}$ & $\begin{array}{c}0.542 \\
(0.023)\end{array}$ & $\begin{array}{c}0.538 \\
(0.023)\end{array}$ & $\begin{array}{c}0.932 \\
(0.006)\end{array}$ \\
\hline & $\operatorname{VAR}(1)$ & $\begin{array}{c}0.181 \\
(0.020)\end{array}$ & $\begin{array}{c}0.124 \\
(0.015)\end{array}$ & $\begin{array}{c}0.094 \\
(0.012)\end{array}$ & $\begin{array}{c}0.093 \\
(0.012)\end{array}$ & $\begin{array}{c}0.473 \\
(0.037)\end{array}$ \\
\hline & $\operatorname{VARMA}(1,1)$ & $\begin{array}{c}0.189 \\
(0.023)\end{array}$ & $\begin{array}{c}0.136 \\
(0.018)\end{array}$ & $\begin{array}{c}0.118 \\
(0.016)\end{array}$ & $\begin{array}{c}0.131 \\
(0.018)\end{array}$ & $\begin{array}{c}0.395 \\
(0.133)\end{array}$ \\
\hline \multirow{3}{*}{$h$} & $\operatorname{AR}(1$ & $\begin{array}{c}0.105 \\
(0.010)\end{array}$ & $\begin{array}{c}0.104 \\
(0.010)\end{array}$ & $\begin{array}{c}0.102 \\
(0.009)\end{array}$ & $\begin{array}{c}0.100 \\
(0.009)\end{array}$ & $\begin{array}{c}0.090 \\
(0.008)\end{array}$ \\
\hline & $\operatorname{VAR}(1)$ & $\begin{array}{c}0.084 \\
(0.011)\end{array}$ & $\begin{array}{c}0.046 \\
(0.007)\end{array}$ & $\begin{array}{c}0.028 \\
(0.004)\end{array}$ & $\begin{array}{c}0.021 \\
(0.003)\end{array}$ & $\begin{array}{c}0.012 \\
(0.002)\end{array}$ \\
\hline & $\operatorname{VARMA}(1,1)$ & $\begin{array}{c}0.094 \\
(0.013)\end{array}$ & $\begin{array}{c}0.053 \\
(0.008)\end{array}$ & $\begin{array}{c}0.035 \\
(0.005)\end{array}$ & $\begin{array}{c}0.029 \\
(0.004)\end{array}$ & $\begin{array}{c}0.002 \\
(0.001)\end{array}$ \\
\hline
\end{tabular}

The first point to note is that with the exception of hours, technology shocks generally explain high and especially low frequency movements in the data much better than at the various business cycle ranges. The dominance of the low frequency range is probably mostly explained by the fact that technology shocks are very persistent in our estimations. The persistence of technology echoes the results reported in Ireland (2001) who finds, “... sharp and decisive evidence in support of a version of the real business cycle model in which technology shocks are extremely persistent but still trend 
stationary" (Ireland 2001, p.705). ${ }^{25}$ In this context, based on evidence from forecast error decompositions, he also draws attention to the fact that "...an increase in the persistence of technology shocks helps the model to explain the behavior of output and consumption even as it hurts the model's ability to explain the behavior of investment and hours worked" (Ireland, 2001, p. 718). This rank ordering also appears to generally hold for the spectral results reported in Table 4, especially for the $\operatorname{VAR}(1)$ and $\operatorname{VARMA}(1,1)$ models.

Complimentary to our forecast error decomposition results, the findings in Table 4 also suggest that adding more complicated error structures generally weakens the explanatory power of the RBC model. This holds uniformly as we move from the $\operatorname{AR}(1)$ to the $\operatorname{VAR}(1) / \operatorname{VARMA}(1,1)$ specifications. In contrast, as we move from the $\operatorname{VAR}(1)$ to the $\operatorname{VARMA}(1,1)$, explanatory power appears to increase again. But based on the size of the standard deviations reported in Table 4, the posterior distributions overlap considerably.

\section{Parameter stability}

Given the evidence of multimodal posterior parameter distributions raised in section 4, suggesting parameter instability, we next examine this issue further for the $\operatorname{VARMA}(1,1)$ specification. To place this topic in context, Ireland (2004 p. 1216) states, "Across the board, the tests reject the null hypothesis of parameter stability. Evidently, important changes have taken place in the postwar US economy that neither the real business cycle model nor the hybrid model's residuals can fully account for. These test results echo and extend the previous findings from Stock and Watson (1996), who record evidence of widespread instability in parameters in VAR models estimated with postwar US data."

To test for parameter stability, we adopt the 1980 breakpoint used in Ireland (2004) and in each step of the estimation algorithm, draw two realisations of the parameter vector. The first one is active in the period 1948:1-1979:4 and the second one in the period 1980:1-2002:2. These two parameter vectors allow for structural breaks in both the economic and measurement/specification error blocks of the model. The likelihood is based on the entire period, and the prior for the parameter vector is calculated from

\footnotetext{
${ }^{25}$ Its worth pointing out that using the estimation methods employed here we found that the data supported the highly persistent trend stationary to difference stationary specification of productivity. Strictly speaking, the data preferred trend stationary productivity in the Hansen model to the alternative which included difference stationary productivity and production re-specified as $Y_{t}=K_{t}^{\theta}\left(A_{t} H_{t}\right)^{1-\theta}$. For further details on why permanent changes in productivity must be modelled in labour augmenting form, see King et al. (1988 pp. 199-200) and additional references therein.
} 
the priors of the two realisations. The results of applying the logmarginal likelihood difference test to the split-sample relative to the full-sample model yields a value of 735.99 indicating a far better fit for the fomer. In other words the data strongly prefer two sets of parameter estimates to one indicating, as others have found, that there has indeed been structural change throughout this period.

Table 5 summarizes measures of location, spread and accuracy for the posterior structural parameter distributions along with the posterior distributions of the eigenvalues and the covariances for the full- and split-sample models. With respect to the economic parameters, although not large, most of the change occurs for $\gamma, \eta$ and $\sigma$. In contrast, there is much more movement in a greater number of parameters in the error block of the model. It is finally interesting to note that, consistent with the finding regarding the improved fit of the split-sample model, the normalised numerical standard errors are uniformly more accurate for the two-sample model than for their full-sample counterparts.

To complement the information in Table 5, Figures 7-9 plot the distributions for the eight structural parameters for the full-sample and the twosub-samples. Generally, the shape of these distributions across all samples indicates that the measured data employed has been informative given that our priors were uniform. However, as pointed out above, several of the parameter distributions for the full-sample in Figure 7 contain multiple modes. In contrast, in the split-sample Figures 8-9, we see that most of the multiple modes have been removed. Generally, the distributions for the longer first sub-sample are better behaved (i.e. more unimodal) than both the fullsample and the second shorter sub-sample distributions. Finally, from Figure 3 we can also see that the break in productivity documented in subsection 4.4 is quite strongly in evidence as indicated by the bimodal distribution for $\rho$.

Thus, it appears that irrespective of whether classical or simulation based methods are employed to estimate DSGE, hybrid DSGE or SVAR models, the issue of parameter stability is vexed. Clearly much more research into this problem is required. We suggest some possible ways forward in the context of our future work with hybrid DSGE models in the conclusions. 
Table 5: Posterior distributions of parameters, $\boldsymbol{\psi}$

\begin{tabular}{|c|c|c|c|c|c|c|c|c|c|}
\hline & \multicolumn{3}{|c|}{ Full Sample } & \multicolumn{3}{|c|}{ 1948:1-1979:4 } & \multicolumn{3}{|c|}{ 1980:1-2002:2 } \\
\hline & mean & s.d. & $\frac{N S E}{\left|\overline{\psi_{i}}\right|} \%$ & mean & s.d. & $\frac{N S E}{\left|\overline{\psi_{i}}\right|} \%$ & mean & s.d. & $\frac{N S E}{\left|\overline{\psi_{i}}\right|} \%$ \\
\hline \multicolumn{10}{|c|}{ Structural parameters } \\
\hline$\beta$ & 0.99094 & $1.09 \mathrm{E}-04$ & 0.00371 & 0.99104 & $9.95 \mathrm{E}-05$ & 0.00000 & 0.98947 & $3.23 \mathrm{E}-04$ & 0.00000 \\
\hline$\gamma$ & 0.00469 & $2.95 \mathrm{E}-06$ & 0.01691 & 0.00469 & $2.77 \mathrm{E}-06$ & 0.00000 & 0.00332 & $8.30 \mathrm{E}-05$ & 0.00000 \\
\hline$\rho$ & 0.99889 & $4.15 \mathrm{E}-05$ & 0.00150 & 0.99970 & $1.05 \mathrm{E}-04$ & 0.00000 & 0.99853 & $2.39 \mathrm{E}-04$ & 0.00000 \\
\hline$A$ & 5.18484 & $3.98 \mathrm{E}-05$ & 0.00022 & 5.18377 & $2.70 \mathrm{E}-04$ & 0.00000 & 5.18386 & $1.08 \mathrm{E}-04$ & 0.00000 \\
\hline$\delta$ & 0.02409 & $3.07 \mathrm{E}-05$ & 0.03691 & 0.02510 & $1.87 \mathrm{E}-04$ & 0.00003 & 0.02419 & $3.76 \mathrm{E}-04$ & 0.00003 \\
\hline$\theta$ & 0.23016 & $4.62 \mathrm{E}-05$ & 0.00543 & 0.23045 & $8.06 \mathrm{E}-05$ & 0.00000 & 0.23031 & 8.88E-04 & 0.00000 \\
\hline$\eta$ & 1.00433 & $7.31 \mathrm{E}-05$ & 0.00246 & 1.00347 & $2.34 \mathrm{E}-04$ & 0.00000 & 1.00290 & $6.87 \mathrm{E}-04$ & 0.00000 \\
\hline$\sigma_{\epsilon}$ & 0.00549 & $2.97 \mathrm{E}-04$ & 0.27404 & 0.01706 & $1.12 \mathrm{E}-03$ & 0.00029 & 0.00607 & $1.17 \mathrm{E}-03$ & 0.00083 \\
\hline \multicolumn{10}{|c|}{ Eigenvalues } \\
\hline$\lambda_{1}$ & 0.79455 & $1.25 \mathrm{E}-03$ & 0.03432 & 0.81417 & $5.72 \mathrm{E}-03$ & 0.00003 & 46 & $2.10 \mathrm{E}-02$ & 0.00008 \\
\hline$\lambda_{2}$ & 0.79455 & $1.25 \mathrm{E}-03$ & 0.03432 & 0.81417 & $5.72 \mathrm{E}-03$ & 0.00003 & 0.90334 & $1.43 \mathrm{E}-02$ & 0.00008 \\
\hline$\lambda_{3}$ & 0.99347 & $3.58 \mathrm{E}-03$ & 0.11236 & 0.96848 & $1.01 \mathrm{E}-02$ & 0.00005 & 0.81363 & $3.33 \mathrm{E}-02$ & 0.00006 \\
\hline$\lambda_{4}$ & 0.01431 & 2.10E-03 & 4.03654 & 0.04156 & $1.57 \mathrm{E}-02$ & 0.00225 & 0.07673 & $1.11 \mathrm{E}-02$ & 0.00065 \\
\hline$\lambda_{5}$ & 0.01370 & $3.58 \mathrm{E}-03$ & 8.27624 & 0.04156 & $1.57 \mathrm{E}-02$ & 0.00154 & 0.07459 & $1.40 \mathrm{E}-02$ & 0.00084 \\
\hline$\lambda_{6}$ & 0.01263 & $4.87 \mathrm{E}-03$ & 12.53870 & 0.03884 & $1.16 \mathrm{E}-02$ & 0.00384 & 0.02385 & $7.55 \mathrm{E}-03$ & 0.00141 \\
\hline \multicolumn{10}{|c|}{ Covariance parameters } \\
\hline$\Sigma_{y y}$ & 0.00007 & $1.02 \mathrm{E}-05$ & 2.45091 & 0.00697 & $9.69 \mathrm{E}-05$ & 0.00006 & 0.00711 & $1.09 \mathrm{E}-04$ & 0.00006 \\
\hline$\Sigma_{c c}^{99}$ & 0.00004 & $6.31 \mathrm{E}-06$ & 2.17252 & 0.00595 & 3.93E-04 & 0.00030 & 0.00598 & $1.10 \mathrm{E}-04$ & 0.00029 \\
\hline$\Sigma_{h h}$ & 0.00003 & $5.66 \mathrm{E}-06$ & 3.35700 & 0.00111 & $1.90 \mathrm{E}-04$ & 0.00077 & 0.00080 & $3.59 \mathrm{E}-04$ & 0.00106 \\
\hline$\Sigma_{y c}$ & 0.00005 & $5.69 \mathrm{E}-06$ & 1.18435 & 0.00031 & $1.81 \mathrm{E}-04$ & 0.00257 & -0.00078 & $3.19 \mathrm{E}-04$ & 0.00104 \\
\hline$\Sigma_{y h}$ & 0.00002 & 4.13E-06 & 2.22671 & 0.00001 & $5.92 \mathrm{E}-05$ & 0.02431 & -0.00067 & $1.27 \mathrm{E}-04$ & 0.00040 \\
\hline$\Sigma_{c h}$ & 0.00002 & 4.01E-06 & 2.83263 & -0.00014 & $2.04 \mathrm{E}-04$ & 0.00667 & -0.00008 & 7.79E-05 & 0.01150 \\
\hline
\end{tabular}


Figure 7: Posterior Distributions (Structural Parameters), Full Sample
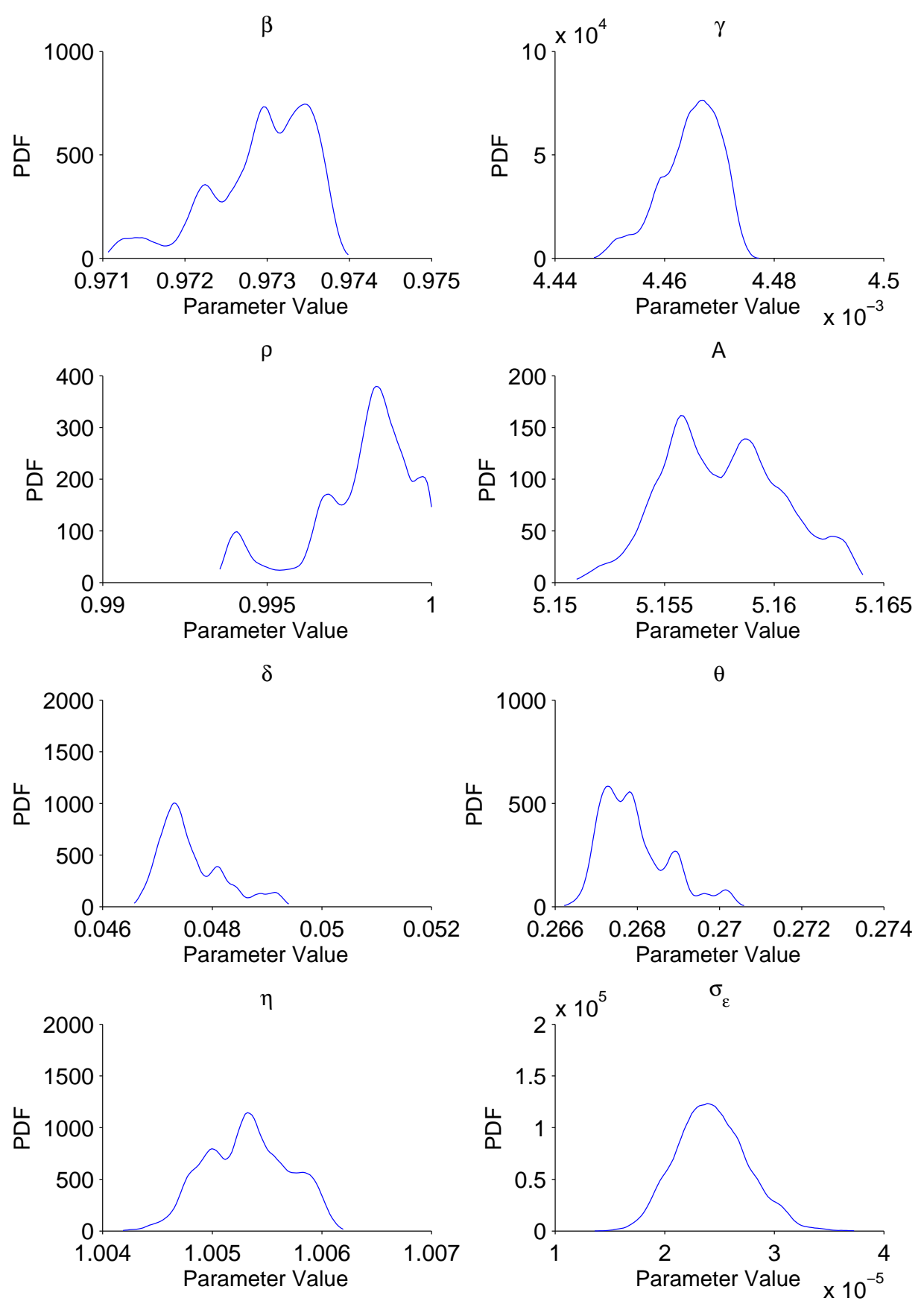
Figure 8: Posterior Distributions (Structural Parameters), 1948:1-1979:4
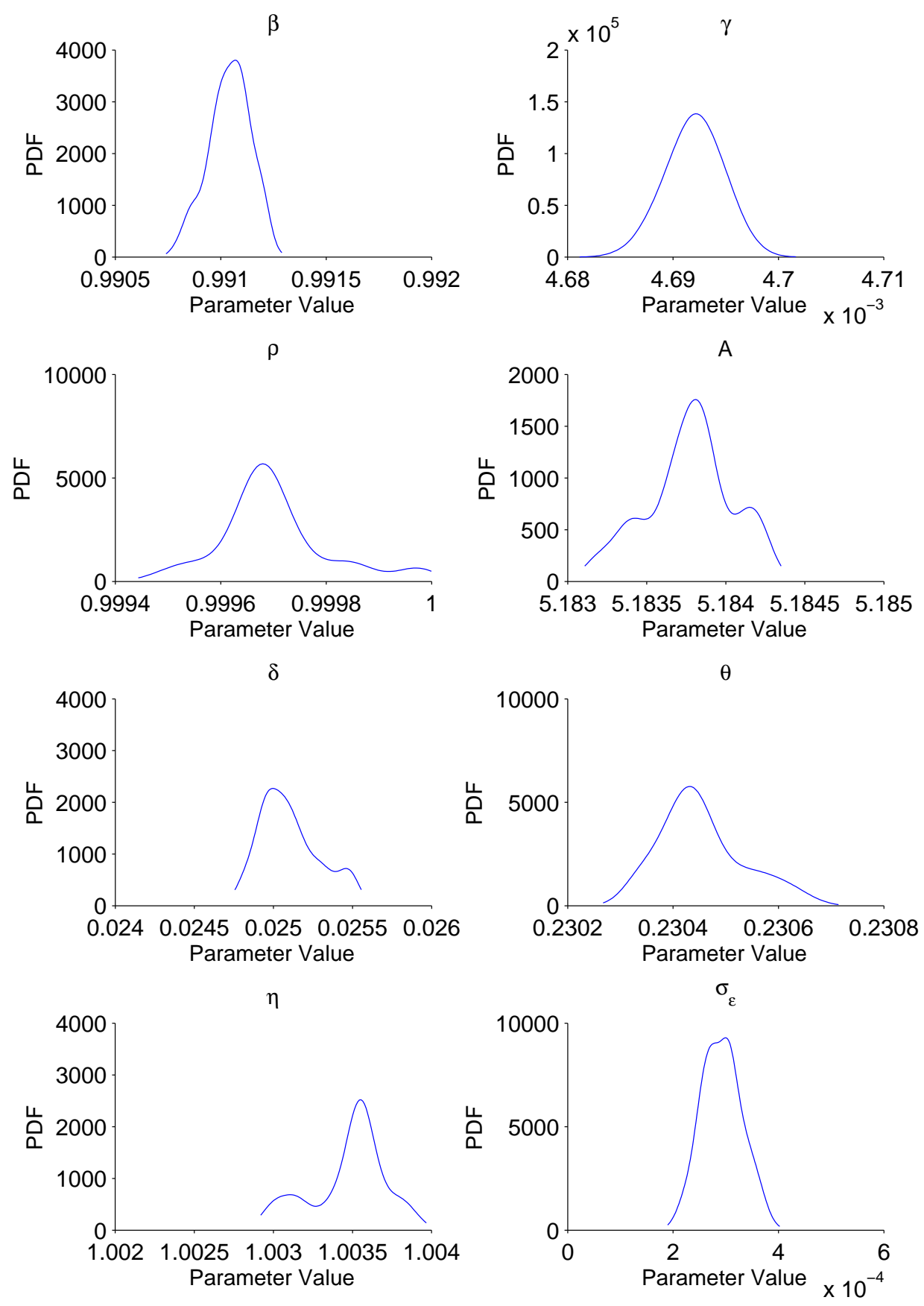
Figure 9: Posterior Distributions (Structural Parameters), 1980:1-2002:2
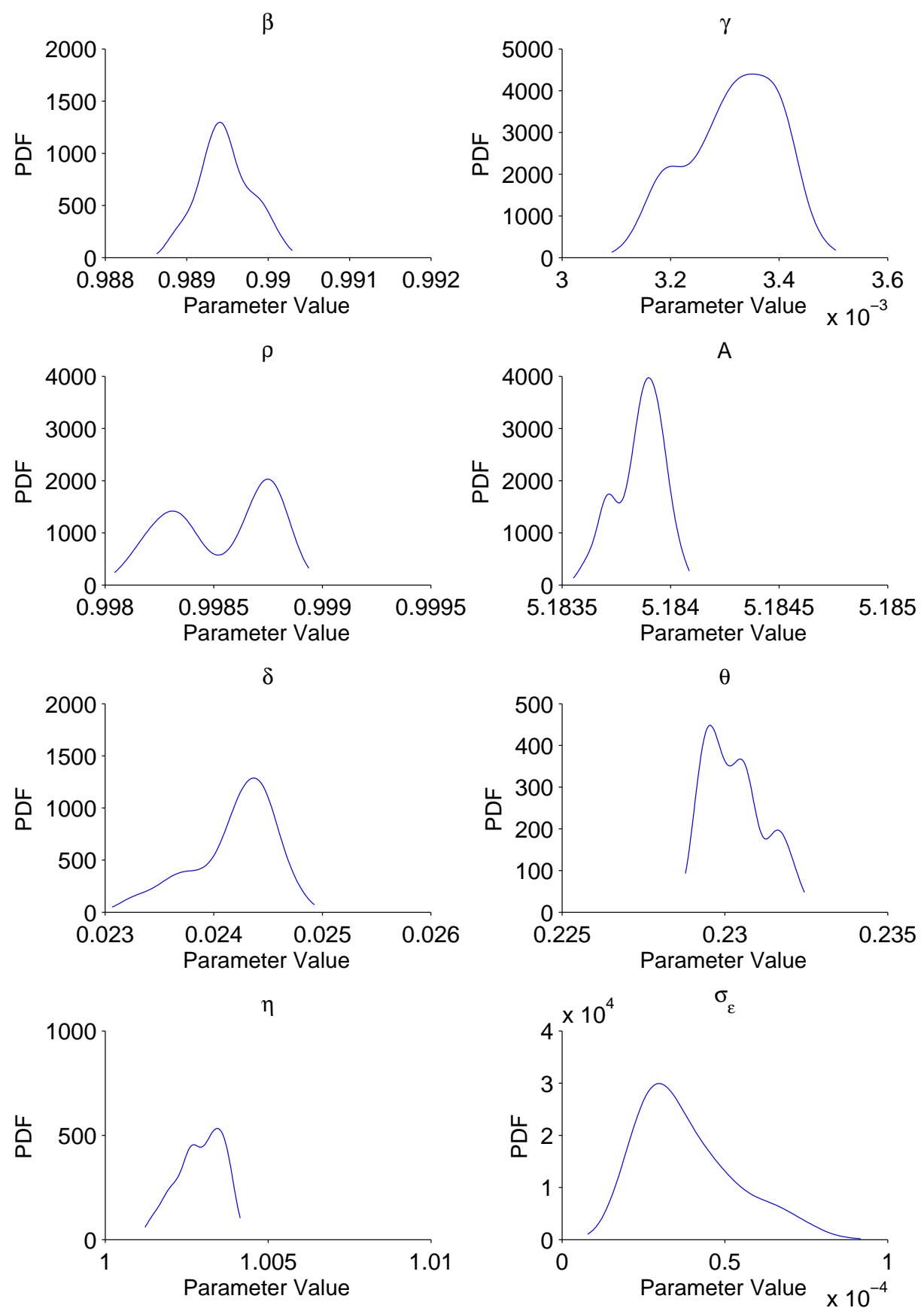


\section{Conclusions and Future Work}

This paper has attempted to contribute to the on-going empirical debate regarding the role of the $\mathrm{RBC}$ model and in particular of technology shocks in explaining aggregate fluctuations. To this end we have extended Ireland's (2001, 2004) hybrid estimation approach to allow for a $\operatorname{VARMA}(1,1)$ process to describe the movements and co-movements of the model's errors not explained by the basic RBC model.

Our main findings are: (i) the $\operatorname{VARMA}(1,1)$ specification of the errors significantly improves the basic RBC model's fit to the historical data relative to the $\operatorname{VAR}(1)$ and $\mathrm{AR}(1)$ alternatives; (ii) despite setting the RBC model a more difficult task under the $\operatorname{VARMA}(1,1)$ specification, technological shocks are still capable of explaining a significant share of the observed variation in output and its components over shorter- and longer-forecast horizons as well as hours at shorter horizons; (iii) the RBC model generally does a relatively better job at matching low and high frequency cyclical movements in the data than at the traditional business cycles ranges; and (iv) the degree of uncertainty associated with the explanatory power of the RBC model much discussed in the literature is perhaps overstated since we find that estimated posterior distributions for the forecast error and spectral decompositions to be quite concentrated.

In future research we plan to further examine the issue of structural stability in a split sample setting but also in the context of time-varying parameters. We would argue that the former is more appropriate for the model's structural parameters, unless of course non-constant structural parameters are part of the theoretical model. On the other hand, varying parameters might usefully be employed to pick up structural change in the a-theoretical VAR(MA) block of the model. Recent successful examples using time-varying parameters in a VAR context include the research of Cogley and Sargent (2005) and Primiceri (2005). Another possible extension would be to modify the basic RBC model to allow for endogenous growth in human capital but still retaining the exogenous process driving productivity in the goods sector. In addition, if an analogous exogenous process is added to the human capital production function, then the relative contributions of the competing productivity processes to explaining the observed variation in macroeconomic aggregates could be quantitatively assessed. Given that our conclusions regarding the usefulness of the basic RBC model are more optimistic than many in the literature, we think these are issues well worth exploring. 


\section{References}

[1] A'Hearn, B. and U. Woitek. (2001). More international evidence on the historical properties of business cycles, Journal of Monetary Economics, 47, 321-346.

[2] Altug, S. (1989). Time-to-build and aggregate fluctuations: some new evidence, International Economic Review, 30, 889-920.

[3] Bencivenga, V. (1992). An econometric study of hours and output variation with preference shocks, International Economic Review, 33, 449471.

[4] Bouakez, H., Cardia, E. and F. Ruge-Murcia (2005). Habit formation and the persistence of monetary shocks, Journal of Monetary Economics, $52,1073-1088$.

[5] Chari, V., Kehoe, P. and E. McGrattan (2007a). Are structural VARs with long-run restrictions useful in developing business cycle theory? Federal Reserve Bank of Minneapolis, Research Department Staff Report 364 .

[6] Chari, V., Kehoe, P. and E. McGrattan (2007b). Business cycle accounting, Econometrica, 75, 781-836.

[7] Chib, S. and I. Jeliazkov (2001). Marginal likelihood from the Metropolis-Hastings output, Journal of the American Statistical Association, 96, 270-281.

[8] Chib, S. and Greenberg, E. (1995). Understanding the MetropolisHastings algorithm, American Statistician, 49, 327-335.

[9] Christiano, L., Eichenbaum, M. and R. Vigfusson (2003). What happens after a technology shock? NBER Working Paper, 9819.

[10] Christiano, L. (1988). Why does inventory investment fluctuate so much? Journal of Monetary Economics, 21, 247-280.

[11] Cogley, T. and T. Sargent (2005). Drifts and Volatilities: Monetary Policies and Outcomes in the Post WWII US, Review of Economic, Dynamics, 8, 262-302.

[12] Cogley, T. and Nason, J. (1995). Output dynamics in real-business-cycle models, American Economic Review, 85, 492-511. 
[13] DeJong, D., Ingram, B. and C. Whiteman (2000a). Keynesian impulses versus Solow residuals: identifying sources of business cycle fluctuations, Journal of Applied Econometrics, 15, 311-329.

[14] DeJong, D., Ingram, B. and C. Whiteman (2000b). A Bayesian approach to dynamic macroeconomics, Journal of Econometrics, 98, 203-223.

[15] Eichenbaum, M. (1991). Real business-cycle theory: wisdom or whimsy? Journal of Economic Dynamics and Control, 15, 607-626.

[16] Fernández-Villaverde, J. and J. Rubio-Ramírez (2004), Comparing dynamic equilibrium models to data: a Bayesian approach, Journal of Econometrics, 123, 153-187.

[17] Fernández-Villaverde, J. and J. Rubio-Ramírez (2005), Estimating dynamic equilibrium economies: linear versus nonlinear likelihood, Journal of Applied Econometrics, 20, 891-910.

[18] Francis, N. and V. Ramey (2005). Is the technology-driven real business cycle hypothesis dead? Shocks and aggregate fluctuations revisited, Journal of Monetary Economics, 52, 1379-1399.

[19] Galí, G. (1999). Technology, employment, and the business cycle: do technology shocks explain aggregate fluctuations?, American Economic Review, 89, 249-271.

[20] Galí, J. and P. Rabanal (2005). Technology shocks and aggregate fluctuations: how well does the RBC model fit postwar U.S. data? NBER Macroeconomics Annual 2004, (ed) M. Gertler and K. Rogoff, 225-88, Cambridge, Mass.: MIT Press.

[21] Gelman, A., Roberts, G., and W. Gilks (1996). Efficient Metropolis jumping rules. In: Berger, J.O., Bernado, J.M., David, A.P., Smith, A.F.M. (Eds.), Bayesian Statistics, Vol. 5. Oxford University Press, Oxford, pp. 599-607.

[22] Geweke (1992). Evaluating the accuracy of sampling-based approaches to the calculation of posterior moments. In: Bernardo, J.M., Berger, J.O., Dawid, A.P., Smith, A.F.M. (Eds.), Bayesian Statistics, Vol. 4. Oxford University Press, Oxford, 169-193 (with discussion).

[23] Gordon, R. (2000). Interpreting the "one big wave" in U.S. long-term productivity growth, NBER Working Paper 7752, Cambridge, MA. 
[24] Greenberg, E. (2008). Introduction to Bayesian Econometrics, Cambridge University Press, New York.

[25] Hall, G. (1996). Overtime effort, and the propagation of business cycle shocks, Journal of Monetary Economics, 38, 139-160.

[26] Hamilton (1994). Time Series Analysis, Princeton University Press, Princeton, New Jersey.

[27] Hansen, G. (1985). Indivisible labor and the business cycle. Journal of Monetary Economics 16, 309-327.

[28] Harvey, A. (1992). Forecasting, Structural Time Series Models and the Kalman Filter, Cambridge University Press.

[29] Ireland, P. (1997). A small structural, quarterly model for monetary policy evaluation. Carnegie-Rochester Conference Series on Public Policy, 47,83-108.

[30] Ireland, P. (2001a). Money's role in the monetary business cycle, NBER Working Paper 8115, Mass.

[31] Ireland, P. (2001b). Sticky-price models of the business cycle: specification and stability, Journal of Monetary Economics, 47, 3-18.

[32] Ireland, P. (2001c). Technology shocks and the business cycle: an empirical investigation, Journal of Economic Dynamics and Control, 25, 703-719.

[33] Ireland, P. (2002). Endogenous money or sticky prices? NBER Working Paper 9390, Cambridge, Mass.

[34] Ireland, P. (2004). A method for taking models to the data, Journal of Economic Dynamics and Control, 24, 1205-1226.

[35] Ireland, P. (2008). Productivity and US macroeconomic performance: Interpreting the past and predicting the future with a two-sector real business cycle model, Review of Economic Dynamics, 11, 473-92.

[36] Kim, J. (2000). Constructing and estimating a realistic optimizing model of monetary policy, Journal of Monetary Economics, 45, 329-359.

[37] King, R., Plosser, C., and S. Rebelo (1988). Production, growth and business cycles: I. the basic neoclassical model model, Journal of Monetary Economics, 21, 195-232. 
[38] Lütkepohl, H. (1991). Introduction to Multiple Time Series Analysis, Springer.

[39] McGrattan, E. (1994). The macroeconomic effects of distortionary taxation, Journal of Monetary Economics, 33, 573-601.

[40] McGrattan, E., Rogerson, R. and R. Wright (1997). An equilibrium model of the business cycle with household production and fiscal policy, International Economic Review, 38, 267-290.

[41] Nordhaus, W. (2004). Retrospective on the 1970s productivity slowdown, NBER Working Paper 10950.

[42] Priestley, M. (1981). Spectral Analysis and Time Series. Academic Press, London.

[43] Primiceri, G. (2005). Time varying structural vector autoregressions and monetary policy, The Review of Economic Studies, 72, 821-852.

[44] Ruge-Murcia, F. (2007). Methods to estimate dynamic stochastic general equilibrium models, Journal of Economic Dynamics and Control, 31, 2599-2636.

[45] Sargent, T. (1989). Two models of measurements and the investment accelerator, Journal of Political Economy, 97, 251-287.

[46] Schorfheide, F. (2000). Loss function-based evaluation of DSGE models, Journal of Applied Econometrics, 15, 645-670.

[47] Sims, C. (1989). Models and their uses, American Journal of Agricultural Economics, 71, 489-494.

[48] Smets, F. and R. Wouters (2003). An estimated stochastic dynamic general equilibrium model for the euro area, Journal of the European Economic Association, 1, 1123-1175.

[49] Stock, J. and M. Watston (1996). Evidence on structural instability in macroeconomic time series relations, Journal of Business and Economic Statistics, 14, 11-30.

[50] Watson, M. (1993). Measures of fit for calibrated models, Journal of Political Economy, 101, 1011-41. 